A. F. MEYER AND ASSOCIATES, INC.

ENVIRONMENTAL NOISE. AND OCCUPATIONAL HEALTH CONSULTANTS

DOE/ET/13557-18

Impact and Compliance

OSHA Corcinogen POIlicy

MASTER

June 26,1980

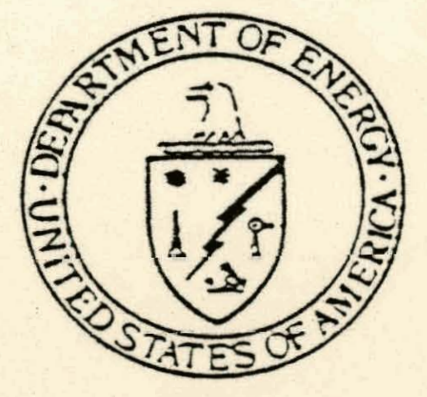

Prepared for

Office of Assistant Secretary for Fossil Energy

U. S. Department of Energy

under

Contract DE-ACO2-ET-13557.AOO1

DISTRIBUTION OF FHS BOSHMEAT IS UNLIMITED 


\section{DISCLAIMER}

This report was prepared as an account of work sponsored by an agency of the United States Government. Neither the United States Government nor any agency Thereof, nor any of their employees, makes any warranty, express or implied, or assumes any legal liability or responsibility for the accuracy, completeness, or usefulness of any information, apparatus, product, or process disclosed, or represents that its use would not infringe privately owned rights. Reference herein to any specific commercial product, process, or service by trade name, trademark, manufacturer, or otherwise does not necessarily constitute or imply its endorsement, recommendation, or favoring by the United States Government or any agency thereof. The views and opinions of authors expressed herein do not necessarily state or reflect those of the United States Government or any agency thereof. 


\section{DISCLAIMER}

Portions of this document may be illegible in electronic image products. Images are produced from the best available original document. 


\section{The following pages are an exact representation of what is in the original document folder.}




\title{
Impact and Compliance
}

\section{OSHA Carcinogen Policy}

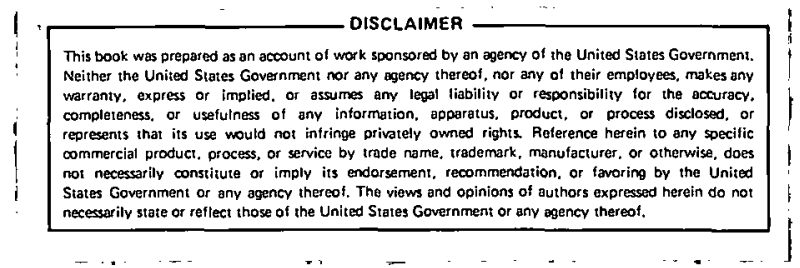

Prepared for:

U. S. Department of Energy

Office of Assistant Secretary for Fossil Energy

Washingtion, D.C.

Prepared by:

A. F. Meyer and Associates, Ine.

\author{
Alvin F. Meyer, Jr. \\ Project Manager \\ Colleen Crowder \\ Research Assistant, Author \\ Sandra Wisniewski \\ Editor \\ Therese Russell, Kay Senn \\ Word Processing
}




\title{
DISCLAIMER
}

This report was prepared as an account of work sponsored by an agency of the United States Government. Neither the United States nor any agency thereof, nor any of their employees, makes any warranty, expressed or implied, or assumes any legal liability or responsibility for any third party's use or the results of such use of any information, apparatus; product, or process disclosed in this report, or represents that its use by such third party would not infringe privately owned rights.

\author{
Distribution \\ DOE/OPTA - 10 \\ AFMA - 2 \\ DOE/TIC - 2
}


Foreword

This document provides an examination of various aspects of the OSHA Carcinogen Policy. To satisfy the dimensions of the Policy's broad, general nature, a two-fold approach has been taken. Throughout, the focus is on the possible effects of the Policy's implementation, but this is first approached as it generally will effect research and compliance activities across broad industry sectors, while specific impacts on DOE are addressed separately. To overview and integrate these approaches, and to provide a quick reference for further information, an outline of information is presented in Chapter III.

General or industry-wide applications are addressed both in the Summary and "Overview" of the Policy (Chapters I \& II) and in the discussion of the Model Standard (Chapter V). Also included is a copy of the Policy itself in the General Industry Standards \& Interpretations Change 10 .

Sections specifically addressed to the major concerns of DOE and its contractors are Chapter IV - a discussion of implications for action regarding the synthetic fuels program Chapter VI - a comparison of the OSHA Model Regulations and the FE OSH Manual Standards for Carcinogens, and finally Chapter VII - a list of known carcinogens in coal gasification/1iquefaction.

Together, these elements illustrate the broad scope of the policy's impact, which economic and other constraining consequences begin to become visible. Measures to minimize these consequences are a common underlying theme to each of the sections.

The Policy's own approach is also of a dual nature. In increasing its flexibility, OSHA placed more of the responsibility upon those who would be regulated. Several items of central concern will now be decided during the individual rulemaking process. Understanding this process is the first and crucial responsibility of those who fall in this category since any action taken to deal with its effects should be beginning now. This is the major implication to DOE and its industry cost share partners of the new statutory requirements. 
IMPACT AND COMPLIANCE

OSHA GENERIC CARCINOGEN POLICY

SUMMARY

Forecasting the total impact of OSHA's new Cancer Policy is difficult due to its general and sometimes undefined nature. Terms such as "lowest feasible level" and "suitable substitute" will remain unclear until individual rulemaking processes demonstrate how OSHA will actually implement the policy. One major factor that will influence implementation is the impending Supreme Court decision regarding the benzene case. A lower court has already ruled that OSHA must show a cost/benefit relationship for rules it imposes. If the Supreme Court's ruling also comes down strongly and clearly in favor of industry, it may be necessary for OSHA to revise parts of its policy. A ruling is expected before the July recess.

Also somewhat unclear is the agency's procedure for selecting chemicals and setting priorities for regulation. What is known is that a Candidate List of approximately 500 chemicals will be released by the agency by July 1. Approximately half of these chemicals will be Category I Potential Carcinogens. These will be chemicals that show evidence of increasing tumor incidence in at least one mamalian study or one human study with or without concordant evidence. To be listed as Category II, chemicals require only "suggestive" evidence of carcinogenic activity. Following the publication of the Candidate List, a Priority List will be drawn from each of the Categories I and II. The Priority Lists will be rough indications of OSHA's priorities, but are not binding. As a result of the policy, issues that may be debated during rulemaking are severely constrained. Listing of a substance as Category I could, in itself, constitute a form of regulation if OSHA considers using the General Duty Clause against these substances. Additionally, the only criteria for issuance of an Emergency Temporary Standard (ETS) is that the substance pose a "grave danger", a definition that is automatically applied to a11. Category I substances.

The Permanent Model Standards are structured on three basic elements that cannot be changed without amending the rule. They are:

1. the PEL ${ }^{2}$ will be set at the lowest feasible level for all Category I substances;

2. the PEL must be achieved primarily through engineering and work practice controls;

3. medical examinations and personal protective equipment must be provided at no cost to the employee.

${ }_{2}^{1}$ For more information, see Chapter II, page 4.

2 Permissible Exposure Limit--see: Chapter V, page 2. 
The Model Standard contains 17 major occupational health concerns, and even though the Standard is "flexible", OSHA may not deviate from the pattern of these 17 points unless it can show good cause. Among the items having the most impact on employers will be the extensive requirements for medical surveillance and record keeping.

Regarding test data, OSHA's criteria for acceptance of epidemiological evidence are extrememly stringent. Fewer than ten studies that meet the criteria are known to have been performed. Regarding use of animal bioassay data, OSHA has rejected the concept that positive results must be obtained in two species. The agency also dismisses arguments regarding false positives. Testing at high doses is recognized as a method which is needed; however, use of such data to determine PEL's may be debated during rulemaking. The rulemaking schedule is as follows:

(1) OSHA initiation of a study of a substance;

(2) publication of an Advance Notice of Public Rulemaking (ANPR) within 30 days;

(3) submittal of evidence within 60-90 days following ANPR publication;

(4) public hearing within 100 days of the ANPR.

OSHA has established a scientific review panel in an attempt to answer claims of inflexibility. Panel members however, are to be exclusively government employees, but OSHA additionally answers claims of inflexibility by pointing to the following safeguards:

(1) NCI, NIEH and NIOSH review the policy triannually;

(2) petitions for review can be filed on a "substantial basis";

(3) the Secretary of DOL can order a review;

(4) "substantial new evidence" can arise in the course of rulemaking.

Much of the final impact of the OSHA Carcinogen Policy depends on the individual rulemaking procedures, since this is where the level of control will actually be decided: Certainly, the policy allows for a more flexible application than did OSHA's originally proposed policy. An opportunity and a responsibility thus exists for both DOE and industry participation in the rulemaking procedure that will ultimately affect them. 
In January of this year, OSHA announced its final generic policy for dealing with carcinogens in the workplace. The public hearing record for this policy is the most extensive in legislative history, totaling over 250,000 pages. As a result of these hearings, some significant changes were made from the original 1977 proposal. The primary objective of these changes was to increase flexibility in the policy. This issue is still the major issue under criticism. The policy is likely to remain controversial for some time, probably with significant attempts at modification. Because of this, and because of the general and sometimes undefined nature of the policy itself, predicting the policy's impact is difficult. One factor involved is the undefined nature of OSHA's use of terms such as "lowest feasible level" and "suitable substitute". It is not known, for example, how great a cost increase a substitute could incur and still be considered "suitable". Further, OSHA advised an AFMA associate that the written compliance program called for in the model standard, will not be necessary unless exposures exceed the Permissible Exposure Limit (PEL).

Another factor influencing how the policy will actually be implemented is the Supreme Court decision on the benzene case. This case, as a basic issue, challenges OSHA's authority to impose rules without performing a cost/benefit analysis. A lower court has already ruled against OSHA on this case, and there are indications that if the Supreme Court decision comes down strongly and clearly in favor of the industry plaintiffs, OSHA may have to revise parts of its policy. A ruling in this case is expecte before the court recesses in July.

Current litigation against the policy (by the American Industrial Health Council, the American Petroleum Institute, and the AFL-CIO) is likely to remain in limbo for some time. The policy has been in effect, however, since April 22nd, pending the outcome of these cases.

How the agency will now proceed with the actual selecting of chemicals and setting of priorities for.regulation is another aspect of the policy that is still unclear. The decision of which substances to prioritize for regulation has been left to administrative discretion. What is known is that there will be a Candidate List of about 500 chemicals. The list will contain about 270 of the 300 chemicals originally proposed last summer, plus about 270 new additions. Of these 500 chemicals, about 250 will be Category I potential carcinogens. These are chemicals for which human evidence in one or more mammalian species (with or without concordant evidence of inceased tumors in humans or one or more mammalian species. Category II substances are not considered less hazardous; there is merely less evidence to indict these substances. The Candidate List will be published in the Federal Reglster at least once each year. The first list may be available from OSHA before the end of June although the promised publication date is July 1. 
From the Candidate List will be drawn a Priority List for each of Category I. and Category II potential carcinogens. The Priority Lists will be rough indications of OSHA's regulatory priorities but are not binding. It would be possible, for example, for OSHA to regulate a chemical on neither the Priority nor the Candidate Lists.

Elements considered by OSHA for determining priorities will include:

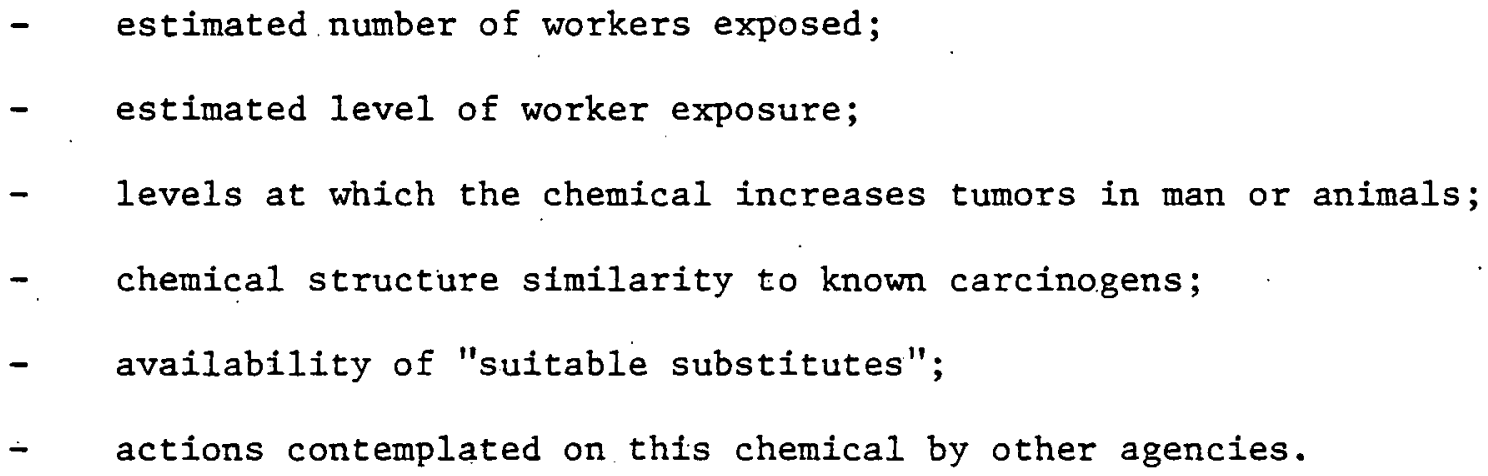

Provisions for public review or challenge of the Candidate and Priority. Lists other than the scheduled tri-annual review are limited. The Secretary of DOL can order a review, or petitions can be filed with the Secretary if "substantial bases" can be shown. Candidate Lists will be based on a "brief scientific review". This has several implications.

1). Issues that may be debated are severely constrained. OSHA will entertain no discussion or submission of information on "issues" resolved in the preamble to the policy, unless there is "substantial new evidence" (1990.145).

2) Rehearing of the validity of the classification system, procedural structure and policy declaration will not be allowed unless :

- available data is inappropriate to the particular substance;

- evidence is submitted as to substantial new evidence;

- there is debate over whether a substance was correctly categorized as I or II;

- there are questions regarding environmental impact, technology, or economics;

- issues arise regarding setting of PEL's for Category II substances;

- appropriateness of any deviation from the model standard is questioned. 
Further, listing of a substance as Category I could in itself constitute a form of regulation if OSHA considers. using the General Duty Clause against these substances. Indeed, OSHA has already proposed such a move against three benzidine-based dyes:

It is also important to note that, in order for a substance to be listed as Category I, OSHA defines it as posing a "grave danger". This definition is also the only qualification necessary for issuance of an Emergency Temporary Standard (ETS). When evoked, an ETS will be similar to the permanent model standards except that any combination of engineering controls and work practices plus personal protective equipment could be used to reach the PEL.

Under the permanent model standards, the PEL must be achieved primarily through engineering and work practice controls. This is a basic element to the policy and cannot be changed without amending the rule. This means that even when engineering controls are insufficient to bring a workplace into compliance, and can be expected to change as new technology develops, currently available controls must be applied. This is likely to entail investment of a great deal of money for the insta11ment of "temporary" controls, but OSHA's record has not shown them to be sympathetic to economic arguments. Apparently OSHA is hoping to force the development of new technology.

The model standards may be used for an individual substance or for a group of substances. The standard for coke oven emissions has set a precedent for industry-specific standards even though the standard is quite specific in defining "coke oven emissions" as a substance.

For a11 Category I substances, the PEL will be set at the "lowest feasible level". With PEL's based on feasibility, not toxicity, all Category I substances will be regulated as though they pose the same hazard. OSHA policy requires the disregarding of potency and doseresponse relationships; this despite much evidence in the hearing record dealing with this issue. This aspect of the policy will have a chilling effect on efforts (by both the academic and industrial community) to provide cost effective solutions by developing methods of risk estimation (through studies such as dose-response, metabolism, DNA repair and others). The appropriate exposure level for Category II substances will be a rulemaking issue. The only exception to this general rule is that, where OSHA deems appropriate, "action levels" and exclusions based on small percentage components ("percentage exclusions") may be included. Thus, in facilities where the exposure level is very low and is entirely due to a very low percentage of the

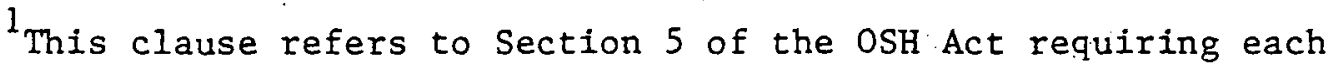
employer to furnish employment "free from recognized hazards". The requirement is thus broad enough to be used against any substance which has not already been regulated. 
chemical in a mixture, requirements for periodic medical monitoring surveillance, training and labeling may be limited, This may well be the case in some fossil fuel processing facilities ${ }^{2}$.

Another aspect of OSHA's policy which is likely to limit development of new data is the criteria for acceptance of epidemiological evidence. The policy sets such stringent requirements for acceptance of human data that in most cases, study results could be used only to indict a substance, never to defend it. OSHA requires that epidemiologic studies be conducted over at least a twenty year period, with a thirty year follow-up. The study cohort must be large enough to detect a fifty percent increase in all tumor sites where tumors are likely to act in humans. Fewer than ten such studies are known to have been performed, and the cost, obviously, is prohibitive.

OSHA also dismisses arguments regarding promoters and metabolic or pharmocological effects as producers of false positives. The agency recognizes testing at high doses as a method which is needed; however in the actual rulemaking, use of such data to determine PEL's can be debated. OSHA has in its policy rejected the concept that positive results must be obtained in two separate species for bioassay results to be conclusive. As a demonstration of the breadth of OSHA's criteria, one positive mouse study would qualify a substance for listing as a carcinogen despite the analysis of one OSHA witness that a mouse is more than one million times as sensitive to epithelial cancer as humans. Clearly, formidable data will be required to contest a proposed rule.

In the rebuttal of OSHA during a rulemaking, the burden is placed upon those who would refute OSHA's evidence to produce appropriate data; OSHA will not set.up protocols. Applicability and content of specific regulations can be debated (i.e. details of monitoring, respiratory protection, protective clothing, etc.).

The agency currently recognizes approximately twelve short-term tests. Their value is seen primarily as screening agents and as confirmation of animal tests. In vitro tests are useful for limited purposes. OSHA agrees that the probability of obtaining a false positive is very low if the results of a well planned in vitro study, as well as those of a properly designed single specie bioassay are both positive. Negative results in the in vitro study are not significant.

The rulemaking.schedule is as follows:

1) OSHA initiation of a study of a substance.

2) Publication of an Advance Notice of Public Rulemaking (ANPR) (within thirty days).

3) Submittal of evidence (within 60-90 days following the publication of the ANPR).

${ }^{2}$ See also Chapter V, page 2 "Permissible Exposure Limit Provisions". 
4) Public hearing (within 100 days of the ANPR). The least amount of time required to complete the regulatory procedure once OSHA decides to proceed against a substance is about seven months. Periods of over a year appear possible.

In an attempt to answer claims of inflexibility OSHA has established a scientific review panel. Industry has accused this action as being cosmetic however, since

1) the Secretary chooses all its members, (who are all to be government employees),

2) the convening of the panel is optional,

3) the panel's findings are not binding, and

4) the issues that it may debate are very constrained.

OSHA, however, rejects industry's accusation that it has "frozen science" and points to the following four safeguards for new evidence:

1) NCI, NIEH and NIOSH review the policy triannually.

2) Petitions for review can be filed on "substantial basis".

3) The Secretary of DOL can order a review.

4) "Substantial new evidence" can arise in the course of rulemaking.

Additionally, OSHA will define the substances covered by each rule when the individual standard is promulgated.

OSHA has also attempted to provide some increased flexibility within the Model Standard. The originally proposed standard included such detailed requirements as frequency of monitoring, among others. The Model Standard in the final rule is more a guideline than a rigid rule; specific requirements are now left to the individual rulemaking process. The agency may decide not to have requirements for one or more of the 17. concerns; but must provide an explanation where it does not establish requirements. There are three basis elements of the Model Standard which cannot be changed or modified without amending the rule. They will be present in every final standard. They are:

- Worker exposure to Category I substances will be reduced to the. "lowest feasible level".

- Permissible exposure levels must be achieved primarily through engineering and work practice controls.

- Medical examinations and personal protective equipment required by the individual standards will be provided at no cost to the employee. 
Several of the requirements of the Model Standard are of particular note due to the large increase in workload their implementation will entail. Sections dealing with Medical Surveillance, Methods of Compllance, Recordkeeping and. Labeling have drawn the most criticism.

Overall, OSHA's new policy will require increasing effort on the part of employers regarding their industrial hygiene, monitoring and recordkeeping programs. It will probably also mean escalated employer involvement during rulemaking. Much depends on these individual rulemaking procedures, since this is where the actual level of control will be decided. The policy's reliance on these individual procedures allows for a more flexible application than did the originally proposed standard. This approach however, has also created the possibility that the policy's implementation will be much less flexible than many of those testifying had hoped. This duality is the nature of a generic rule, and may explain why both sides of the issue have filed legal challenges. 
III

IMPLICATIONS TO ASFE

OF

OSHA "GENERIC CANCER REGULATION"

29 CFR 1990

"IDENTIFICATION, CLASSIFICATION, AND

REGULATION OF POTENTIAL OCCUPATIONAL CARCINOGENS"

\section{SUMMARY--BACKGROUND}

A. Final Rule Promulgated - January 22, 1980.

B. Original Draft - January, 1977.

C. Published in Federal Register October, 1977.

D. Lengthy Public Hearings - Total Record 7,250,000 pages.

E. Final Rule - Significant Differences V13 Proposed.

F. Preamble to Regulation -273 pages $=$ In depth review and disposition of key issues.

G. US COC and AFL-CIO and Union suing OSHA.

II. SUMMARY--OSHA APPROACH

A. Not really a "generic regulation".

1. Establishes General Policy (1990.101-.106).

2. States Regulatory Policy (1990.111-112).

3. Requires OSHA to Set Priorities for Specific Regulatory Action (1990.121-.133).

4. Prescribes Procedures for Regulatory Action (1990.141$.147)$.

5. Includes Model Standards to be used as Guidelines for Specific Regulations (1990.151-.152).

B. OSHA forecloses any further discussion or submission of information on "Issues" resolved in the Preamble, unless "substantial new issues" or "substantial new evidence" (1990.145).

1. Rehearing of validity of classification system, procedural structure, policy declaration - not allowed. (See Chapter IV, page 3, paragraph 3.)

2. Result - arguments regarding personal protection versus engineering and work practices; and as to "lowest level feasible" by such means will not be entertained.

3. Model Standard requirements are "flexible" and not mandatory BUT - Secretary DOL must explain why deviations were made as principles. (See Chapter II, page 8 , paragraph 3, and Chapter IV, page 1.)

4. Applicability and content of. Specific Regulations, however, can be debated, e.g. details of monitoring, respiratory protection, protective clothing, medical examinations, etc. 
C. OSHA cites coal tars, soot, and "excess of cancer in workers where petroleum refining is carried on" among bases for the Regulation - This is not an allowable issue regarding specific regulations unless "substantial new evidence".

III. IMPLICATIONS TO DOE

A. Need for increase in research and data collection activity.

(See Chapter IV, page 1, paragraph 2.)

1. Need to organize and condense health effects data for efficient utilization during rulemaking (limitation of issues by OSHA).

2. Need for early DOE involvement.

3. Pending OSHA/NIOSH review of synfuel industry.

a. Chemical similarity of a number of coal derived substances to known carcinogens. (Chapter IV, paragraph 3.)

b. Need for DOE to anticipate and respond.

B. Need to develop a mechanism for data submitted to OSHA for use in developing Candidate List. (Chapter IV, paragraph 3.)

1. Will focus DOE hygiene and surveillance efforts on possibly carcinogenic substances. (Chapter IV, page 3, paragraph 1.)

2. Will provide documentation of information required.

C. Information provided OSHA must be complete and consistent in content and format with OSHA requirements. (Chapter IV, page 3, paragraph 2.)

1. Burden of producing appropriate evidence is on DOE and contractors - OSHA will not set up protocol.

2. Availability of DOE health research experts to interpret information during rulemaking will be essential. (Chapter IV, page 3 , paragraph 2.)

D. Need to determine types and combinations of substances associated with each process. (Chapter IV, page 4, paragraph 1.) 1. The OSHA Standard regulating "coke oven emissions" may have set a precedent. (Chapter IV, page 4, paragraph 1.)

2. Possibility of OSHA regulation of emissions from a specific synfuel proçess.

E. DOE need to have input regarding how specific or general standards are and what groups, combinations or mixtures are established.

F. Impact of Substance Placement on Candidate List.

1. Possibility of OSHA use of general duty clause against any substance so 1 isted 3 benzadine dyes have already been moved against. (Chapter IV, page 4, paragraph 2.)

2. Issuance of an ETS also possible against any listed Category I substance.

3. DOE needs mechanism for anticipating and participating in such action (Guidance should be provided to DOL as to what constitutes grave danger to synfuel plant workers). 
4. No provisions for review or challenge of Candidate and Priority Lists except for the triannual review. (Chapter IV, page 5, paragraph 1.)

5. DOE should anticipate above review and respond through support of public participation or through liaison with NCI, NIEHS, and NIOSH.

IV. KEY ISSUES TO ASFE ADDRESSED BY OSHA

A. Rationale and need for Policy.

1. Previously cited "indictment" of coal products and refining.

2. Smoking not a further issue.

3. Possibility of multiple causation recognized but not allowable for debate.

B. Role of Epidemiologic data. (Chapter IV, page 5, paragraph 2.)

1. Little credence to be given to negative studies, in face of positive animal data.

2. Positive epidemiologic data, in absence of animal or in vitro data has credence.

3. Small scale epidemiologic data $+=$ Presumptive Category I, Suggestive Data = Category II.

4. OSHA has specified guidelines as to what constitutes acceptable Epidemiologic data - leaves door open however, regarding specific regulations.

5. OSHA goes to great lengths to set aside acceptance of "negative epidemiologic studies" as proof of "no hazard" AND. to reiterate - any positive human evidence is ipso facto cause for regulation.

6. No debate on:

a. Evidence in humans - as above.

b. Positive animal data overrides negative epidemiologic data.

c. Epidemiologic studies may help in priority setting but given no credence in permissible levels.

7. OSHA Epidemiology Criteria.

a. Studies must be $20-30$ years or longer.

b. Must show a $50 \%$ increase in all body sites where tumors are likely to act in humans to justify a negative finding.

c. Documented reasons for predicting action in humans must be provided. Extrapolation of animal data will not be considered as evidence.

8. Virtually impossible for DOE or its contractors to meet OSHA criteria.

C. Use of Animal Bioassay Data. (Chapter IV, page 6, paragraph

2.)

1. Almost direct analogue to FD\&C Act "Delaney Clause" positive animal test $=$ Regulatory Action. (Note regarding Cross Walk arrangements with EPA trigger consideration for regulation.) 
2. OSHA dismisses false positive problem.

3. Testing at high dose rates recognized as needed - in actual rulemaking, use of such data to determine permissible levels can be rebutted.

4. OSHA rejects argument that positive results must be found in two species.

5. OSHA rejects threshold as no effect level.

6. OSHA will not set protocols; puts. burden on those who could refute data to produce adequate data. OSHA will use expert scientific panels to evaluate data.

7. OSHA dismisses arguments regarding role of promoters, and metabolic or pharmacological effects as producers of false positives.

D. Role of Short Term Tests. (Chapter IV, page 9, paragraph 7.) (Major significance because of present DOE emphasis on use of such in vitro procedures.)

1. OSHA considers short term tests as primary use in screening, and as confirmation of animal tests.

2. Approximately 12 such tests recognized by OSHA.

3. OSHA concludes in vitro tests are useful for limited purposes. Agrees very low probability of false positive if a well planned in vitro and a properly designed single specie bioassay both give positive results. Negative in vitro are not significant.

4. Major need for review of current ASFE programs and Cross Walk with TSCA (EPA requirements).

5. OSHA position almost identical with Interagency Regulatory Liaison: Group, EPA (TSCA and proposed air miscellaneous Cancer Regulations) and FDA.

E. Use of Structural Similarities. (Chapter IV, page 2, paragraph 2.)

1. OSHA will utilize chemical structure similarity as basis for regulation where there is strong $\mathrm{CA}+$ evidence on a member of the group - expert scientific judgement will be used.

2. Since a number of coal derived chemicals are similar to currently identified carcinogens (PNA, BAP, etc.) high probability of early OSHA action regarding priority test. (Recent NACOSH meeting interest.)

F. Risk Assessment, etc. (Chapter IV; page 8.)

1. OSHA concludes State of Art doesn't permit use other than for:

a. development of priorities;

b. estimation of reduction of risk as a result of regulation if adequate data exists.

G. R\&D facilities may be able to obtain some exemption on basis of lower risk through "percentage exclusions" or "action levels" set at individual rulemaking.

H. Amendments to Policy and "Freezing of Science"? (Chapter IV, page 5, paragraph 1.) 
1. Agrees to define substances to be covered by each rule.

2. OSHA rejects contention that truly new information is foreclosed-four safeguards:

a. NCI, HIEHS, NIOSH - review triannually.

b. Petitions can be filed - substantial basis.

c. Secretary DOL can order review.

d. New or substantial evidence arises in course of specific rulemaking.

I. Classification of Carcinogens (Chapter II, pages 2 and 3 ).

1. OSHA modifies original three categories and accepts need for flexibility.

2. OSHA agrees to set priorities for regulations lists to be published in FR.

3. First list to be based on:

a. NIOSH "Clements List";

b. EPA Inventory, etc. under TSCA;

c. OSHA and NIOSH presently identified substances.

4. First list due July 1, 1980, then every six months.

5. Category $I$ = evidence of 'carcinogenicity in humans, two or more mammalian species, or one specie if other studies positive.

6. Category II = Carcinogenicity in one mammalian species; evidence is only suggestive or positive in one specie -not replicated.

7. In sum - Ames Test is of no value.

J. Limitation of Issues in Rulemaking (Chapter IV, page 3, paragraph 3 ).

1. Only evidence directly relevant to issues in the specific substance rulemaking to be allowed, unless:

a. The available data is not appropriate to the substance (s);

b. Evidence is submitted as to new evidence;

c. Whether OSHA correctly selected Category I or II;

d. Questions regarding environmental impact as to Technology and Economics in lowest feasible exposure level;

e. Relevant to setting of levels regarding Category II;

f. Issue relates to substitution of non $C A$ for $C A$.

2. To extent that a proposed regulation differs from a model standard, as to appropriateness of that deviation.

K. Model Standards - Major points affecting DOE. (see Chapter V.)

1. Scope and Application - "percentage exclusions" or action levels may be established during individual rulemaking by facilities with very low exposure. (Chapter V, Page 1.)

2. Methods of Compliance (Chapter V, page 3).

a. Predominance of engineering and work practices controls.

b. Written compliance program. 
3. Medical Surveillance (Chapter V, page 6) -extensive requirements may be more costly to remote DOE facilities.

4. Recordkeeping (Chapter V, page 9) --

a. Nature of requirements may call for computer assistance for compliance.

b. Possibility that simflar records may be required in future for all employees, regardless of exposure. 


\section{IMPACT OF THE OSHA CARCINOGEN POLICY}

\section{ON THE LOE SYNFUELS PROGRAM}

The impact of the OSHA Carcinogen Policy to DOE depends primarily on two things. The first factor influencing implementation will be the Supreme Court decision on the benzene case, expected before July. If the lower court ruling indicating that OSHA must show a reasonable cost/ benefit ratio to implement its rules is upheld, the policy may have to be revised. The second, and possibly most important factor influencing the effect of the policy on DOE, will be the action of DOE itself. It must be remembered that this policy is a generic rule, and much of what it contains requires a "wait-and-see" posture on the part of those affected in order to know the total impact. Neither DOE nor anyone else affected by the policy, however, can afford to wait until "after the standards are set" to begin assessing what their needs will be. This standard setting process will occur on a continuing basis for the foreseeable future, and the time for DOE to become involved through research and data submittal is before and during this process.

DOE should involve itself through increased research and data collection activity. This involvement is critical for several reasons. OSHA has severely limited issues that may be debated during rulemaking. The policy is quite specific in defining the scope and limitations of data and issues and evidence that may be considered. Effort will be required by DOE to organize and condense the health effects data base for efficient utilization in the rulemaking process. Additionally, there are early indications that an intensive OSHA/NIOSH review of the synfuel industry to determine candidate substances for regulation is pending. Among the bases for the regulation, OSHA has cited coal tars, soot, and "excess of cancer in workers where petroleum refining is carried on". Substances that are present in the synfuel process will also be identified from review of other industries. Clearly, to be effective, DOE involvement must begin early, with the selection of candidate substances for Priority Lists and continue through the drafting of the exact provisions of each proposed standard.

The OSHA policy states that chemical structure similarity will be utilized as a basis for regulation. Since a number of coal derived chemicals are similar to currently identified carcinogens (PNA, BAP) ${ }^{1}$, there is a high probability of early action regarding the above mentioned OSHA/NIOSH review. Interest in such a review was expressed, at a recent NACOSH meeting. DOE, its contractors, and private companies receiving DOE development funding; need to anticipate this action and support the OSHA/NIOSH data collection and analysis efforts. Submittal of data for use in establishing the Candidate List is provided for in the Policy, and DOE should develop a mechanism for data submittal on possibly carcinogenic substances found in synfuel processes. The submittals should indicate, using the criteria in par. 1990.112,

$\overline{1 \text { (poly nuclear aromatics, benzo alpha pyrene) }}$ 
whether DOE considers the substances possible Category I or II carcinogens, and recommend whether each substance would be placed on the respective Priority Lists. (Although the first list is to be published by July 1 , additions to the Candidate List will be published at least every six months.) The effect of this effort on the part of DOE will be to focus its own industrial hygiene and medical surveillance efforts on those processes with which potential carcinogens are associated, in order to document the information required under paragraph 1990.132: "Factors to be Considered".

DOE's extensive health research activities should also be utilized in the assembly and evaluation of the data base that will support the activities under paragraph 1990.143: "General Provisions for use of Human and Animal Data". This will ensure that information on substances in synfuel processes that might be regulated under the Policy is complete, consistent in content and format with this paragraph, and made available to OSHA. OSHA has refused to set up protocols for acceptance of data, thereby placing the burden on DOE and its contractors to produce appropriate evidence when refuting data. During the rulemaking process, it will be essential for DOE health research experts to be available to interpret information in the context of the intended standard.

Only evidence directly relevant to issues in the specific substance rulemaking will be allowed, unless:

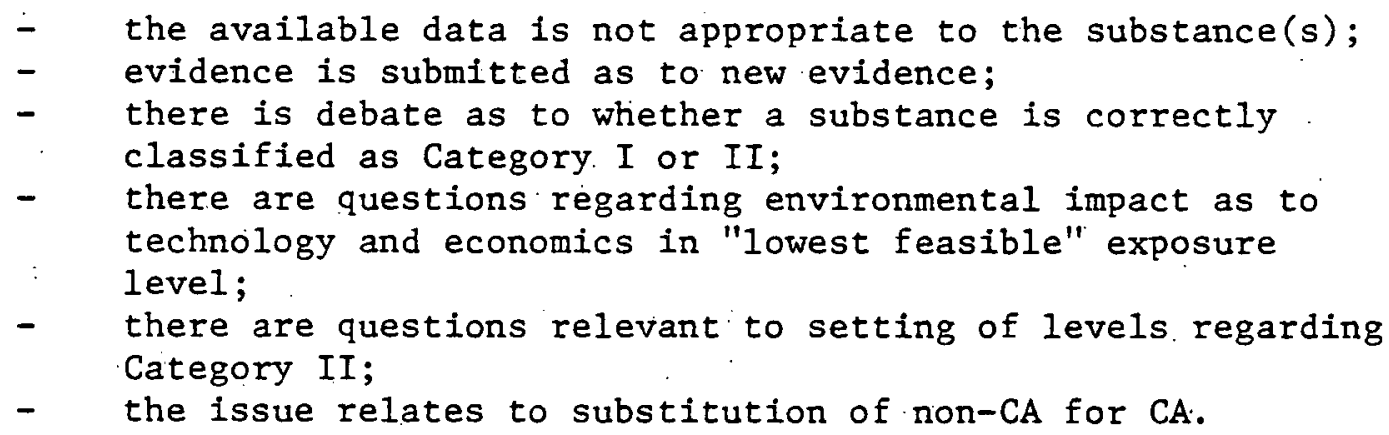

Further data collection efforts will be needed to determine which types of substances and which combinations of these substances are associated with each process. Although the Model Standards provide for the identification of a substance by CAS registery number, the definition of "coke oven emissions" may have set a precedent that will allow regulation of emissions from a specific synfuels process. Additionally, a standard can be set on a general bas1s. For example, "benzene soluble particulates in an area where (suspected carcinogen) is present" could be regulated, regardless of whether lie source of the particulates is the suspected carcinogen. DOE must have some inputs into how specific or general such standards are, and what groups, mixtures or combinations are established.

Of possible immediate impact is the fact that OSHA retains the option of using the reneral Duty Clausc against a substance. If OSHA exercises this option, placement of a substance on a Candidate List 
could in itself constitute a form of regulation. OSHA has already made such a move in the case of three benzadine-based dyes. It is also important to note that an Emergency Temporary Standard (ETS) could be issued against any substance that OSHA believes poses a "grave danger" and that OSHA also defines any substance listed as Category $I$ as posing a grave danger. Because of the immediate and profound effects of the issuance of an ETS, DOE needs a mechanism for anticipating and participating in such an action. For example, determination of what DOE considers a "grave danger" to a worker at a synfuels plant in the context of the Cancer Policy is required to provide guidance to DOL in issuing an ETS that would affect these plants.

In light of the possible impacts of placement on a Candidate list of any substance used, DOE should be aware of the limited provisions for public review or challenge of the Candidate and Priority Lists. The first is the tri-annual review of the policy scheduled by OSHA. DOE should anticipate this review and respond either through support of its contractors and/or industry through the public participation mechanism, or through liaison with the agencies involved with the Sclentific Review Panel and Advisory Comittee. This Panel will be responsible for evaluation of data, including data pertaining to chemical similarity of substances to known carcinogens, and animal bioassay data. Panel members are chosen by the Directors of NCI, NIEHS, and NIOSH. DOE already maintains working arrangements with these agencies, and these should be utilized. Other safeguards are:

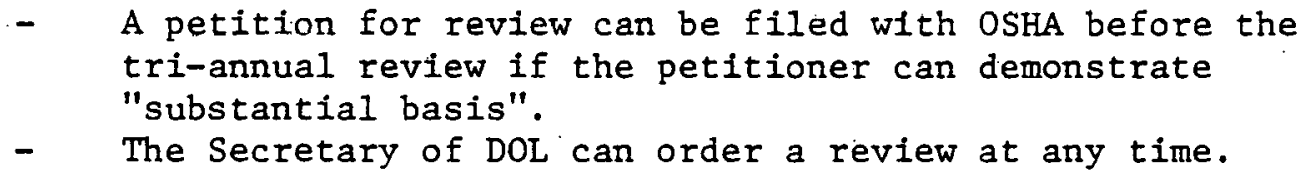

Following are the key issues to DOE addressed by OSHA:

\section{Epidemiologic Data}

OSHA has specified guidelines as to what constitutes acceptable Epidemiologic data; however, there will be no specific regulations on this subject. OSHA has gone to great lengths to set aside acceptance of "negative epidemiologic studies" as proof of no hazard. However, the OSHA criteria for such studies are so stringent as to make it virtually impossible for DOE or its contractors to meet them. In fact, only 10 studies that would meet the criteria are known to have ever been performed. 2 Epidemiologic studies will probably not be economically feasible in the future, in light of the fact that negative results would be overruled by positive results from an animal bioassay, wh1ch is obviously much cheaper to perform. No debate will be heard on this point. Studies not meeting OSHA's stringent criteria could be used only to indict a substance, never to defend it. Further, while epidemiologic evidence may be considered in priority setting, it will be given no

2 Fred D. Hoerger and James $\mathrm{W}$. Conder, "Deficiencies of Science Policy in OSHA's Generic Cancer Regulation". Presented at the workshup of the New York Academy of Science on "The Management of Assessed Risk for Carcinogens." March 17-19, 1980. New York, New York. 
credence in setting permissable exposure levels. No debate on this issue will be entertained during rulemaking. Positive human evidence will be automatic cause for regulation. OSHA's criteria are as follows:

- Studies must be performed over at least a 20-year period, with a 30 year follow-up.

- The study cohort must be of adequate size to detect a $50 \%$ increase in all tumor sites where tumors are likely to act in humans, to justify a negative finding.

\section{Animal Bioassay Data}

The OSHA position on animal bioassay data is almost directly analogous to the FD\&C Act "Delaney Clause" 3 in that it is assumed that positive results from an animal test will trigger regulatory action. It is important to note that positive results from one animal bioassay is all that is required to qualify a substance as Category I under certain circumstances. OSHA has rejected the argument that positive evidence must be obtained in two species in order to indict a substance.

OSHA has also dismissed the false positive problem. Arguments regarding the role of promoters, and metabolic or pharmocological effects as producers of false positives will not be heard. Smoking will not be a further issue. Further, OSHA maintains its position that . testing at high dose rates is a method which is recognized and needed. However, use of such data to determine permissible exposure levels can be rebutted during the actual rulemaking. Again, OSHA will not set up protocols for data.

Role of Short Term. Tests

This area is specifically of interest to DOE because of present emphasis on use of in-vitro procedures. OSHA recognized approximately 12 such tests, but considers their primary function to be limited to use as screening agents, and as confirmations of animal tests, agreeing that there is very low probability of obtaining a false positive where one well planned in-vitro replicates a properly designed single specie bioassay. Negative in-vitro evidence, however, is not significant.

This position is almost identical with the Interagency Regulatory Liaison Group, EPA (TSCA and proposed miscellaneous cancer regulations) 4 and FDA. In light of this, such procedures as the Ames test become of practically no value since, again, such a procedure could be used only to indict a substance, never to defend it. Further, the objective of saving time, money, and resources by using short term tests is eliminated by the requirement calling for concurring animal evidence. The OSHA position on short term tests implicates a major need for review of current ASFE programs and cross walk arrangements with TSCA (EPA requirements).

3 The Federal Food, Drug \& Cosmetic Act, Section 409 (c)(3)(A)

4 TSCA teeting requirements are quile complicated. For a complete description, see AFMA report DOE/ET/13557-2. 


\section{Risk Assessment}

OSHA's policy on the value of risk assessment is likely to have a major negative impact on the development of this art. OSHA policy requires the disregarding of potency and dose-response relationships. Wherever possible, the PEL will set at the "lowest feasible level", without regard to the toxicity of the substance. Thus, studies such as dose-response, DNA repair, and metabolism can no longer be used by R\&D facilities in an attempt to obtain exemptions based on lower risk. Such facilities may qualify however for the percentage exclusions and action levels discussed in Chapter $V$ under Section (a), Scope and Application, page 1.

OSHA has concluded that the state of the art of risk assessment only permits use of these studies for: 1) the development of priorities and 2) estimation of risk reduction where "adequate" data exists.

\section{The Model Standard}

Several of the issues addressed in the Model Standard will have a major impact on DOE. A point by point discussion of the Model Standard is found in Chapter $V$.

In conclusion, extensive effort will be required of DOE in response to this policy, but the bulk of the work may need to be performed far before the standards are set; that is, before and during the individual rulemaking process. Early and thorough research and data collection. involvement will be in the best interest of DOE not only in complying with the standards set, but also in ensuring that those standards are reasonable and accurately in the best interest of worker health and safety. 
THE MODEL STANDARD

OSHA's proposed standard of $2 \frac{1}{2}$ years ago contained a number of detailed requirements such as required frequency of monitoring, frequencies and exposure cut-off points required for certain medical procedures, etc. The model standard in the final rule represents an attempt by OSHA to increase the flexibility of the standard, making it more a guideline than an inflexible pattern. The specific requirements for each of the 17 major occupational health concerns (such as exposure limits) are now to be determined during the individual chemical rulemaking process. Each standard must, however, contain provisions for each of the major concerns, unless OSHA cites a reason to the contrary. Debate on the appropriateness of any deviation from the model standard is an allowable issue during rulemaking. Following is a brief explanation of each of 17 concerns.

a) Scope and Application

This section will determine to whom the standard applies, as well as defining those who are specifically excluded. Where OSHA deems it appropriate, "action levels" and exclusions based on small percentage components ("percentage exclusions") may be included. A facility may obtain a "percentage exclusion" during an individual rulemaking if there is a very low exposure at the worksite which is due entirely to a very low percentage of the chemical in the mixture. Similarly, evidence to support an "actions level" may be presented at the individual rulemaking. If OSHA accepts this evidence, requirements for periodic monitoring, medical surveillance, training and labeling may be limited. Such a ruling would clearly be a boon to R\&D facilities. DOE health research activities should be organized in anticipation of this procedure.

\section{b) Definitions}

Any necessary definitions will be provided.

c) Permissible Exposure Limit Provisions (PEL's)

This limit will be at the "lowest feasible level" for Category I substances. Determination of the limit will take: into consideration technological and economic factors presented during individual rulemaking. The PEL for Category II substances will be determined "as appropriate", rather than being restricted to the "lowest feasible level". Whether or not "ceiling limits" and "eye and dermal 1imits" are necessary will also be an issue for individual rulemaking. A no exposure requirement may be induced if there are "suitable" substitutes. Active participation in the rulemaking process may be required on this issue for DOE and other affected parties to ensure that appropriate consideration is given to economic factors. Exposures will be time-weighted averages (TWA's). 
The fact that OSHA intends to regulate exposure to the lowest feasible level for Category 1 substances and that this must be achieved primarily through work practice and engineering controls probably indicates that a great deal of money will be spent on the institution of temporary controls. OSHA will require that the best available engineering controls be applied, even when insufficient to bring a workplace into full compliance. Methods for control are bound to change as technology advances, requiring backfit or replacement of old technology. Apparently, OSHA is hoping to force the development of new technology to move more quickly.

d) Notification of Uses and Emergencies

Employers will notify OSHA within a specified.time period of within 30 days of introduction of a potential carcinogen (Class I or II) of :

- location of place of employment.

- estimated number of exposed employees.

OSHA must also be notified of any emergency release of the chemical caused by equipment failure, etc.

e) Exposure Monitoring

Exposure monitoring is to be done on the basis of eight-hour samples. The specific methodology of the monitoring will be determined during individual rulemaking, as will periodic monitoring requirements (quarterly, annually, etc.). Specific accuracy requirements may also be included. Employers are required to notify each employee of monitoring results, and where exposures exceed the PEL, include a statement to this effect, along with a description of action being taken to reduce the exposure.

f) Regulated Areas

Such areas will be required where Category I substance cuncentrations are in excess of the PEL. This is not a rulemaking issue for Category I substances, but can be debated for Category II substances. Establishing regulated areas will require marking and notification of boundaries and administrative control to prevent unauthorized personnel from entering. Eating and smoking must also be prevented in'these areas.

g) Methods of Compliance

Engineering and work practice controls must be used to reduce exposures to the PEL except where "the employer establishes such controls are not feasible". This was one of the most hotly debated points of the entire policy. (Again, "temporary" controls are an issue.) Within a time specified in the final standard the employer must submit a written compliance program to include:

a description of operations resulting in exposure; 
- engineering controls for each process;

- a report of technology considered to meet the PEL;

- a detailed schedule for implementation of controls;

- other relevant information requested by OSHA.

Supplemental respirators may be used to achieve the PEL only after other means have been exhausted. This written plan and its implementation is the major undertaking required by the standard. In many cases, DOE will already have planned for the timetable requirements under SARS; however, this OSHA mandate may provide some new problems regarding the legal aspects of failing to meet one's own timetable. Apparently, OSHA only intends to require the written compliance program from workplaces which exceed the PEL. Thus, those workplaces which have obtained percentage exclusions will be exempt from this requirement as we1l.

h) Respiratory Protection

Respirators are to be used only:

- during the time period necessary to implement and install engineering and work practice controls;

- where the employer has established that engineering and work practice controls are not feasible;

- in work situations where engineering and work practice controls are insufficient to reach the PEL;

- in emergencles.

Respirators are to be selected from a list provided in the final standard and provided to employees at no cost. Employers shal1 assure proper tit (OSHA will specify qualitative or quantitative fits as appropriate).

i) Protective Clothing-Equipment

Protective Clothing-Equipment must be provided to employees at no cost where eye and/or skin exposure is hazardous. Employers shall clean, maintain and replace clothing and equipment. This would apply to Category I and II substances. Specific requirements will be decided at each rulemaking.

j) Housekeeping

A program to minimize accumulation of potential carcinogens is required to be implemented. It must include periodic scheduled routine housekeepling, periodic cleaning of dust collection systems, and maintaining clean surfaces. Employees are to be informed of the program. 
k) Waste Disposal

This section prohibits dispersion of carcinogenic wastes into the workplace or the workplace of downstream contractors. It is not yet known whether "downstream contractors" will be interpreted to apply to landfills, and if so, what specific modes of disposal will be determined to be appropriate. Also unclear is whether this would fall under RCRA (Resource Conservation and Recovery Act) or OSHA jurisdiction. This issue will be addressed during Individual rulemaking.

\section{1) Hygiene Facilities and Practices}

Hygiene facilities and practices will be required for Category I substance where exposures exceed the PEL or where employees must wear protective clothing. Hygiene facilities and practices are discretionary for Category II substances. Requirements for showers, change rooms, "clean" and "dirty" locker rooms and filtered air lunchrooms will be determined in individual rulemaking. Requirements in this area could result in new building requirements.

m) Medical Surveillance

A medical surveillance program must be instituted for employers specified in the individual rulemakings ( on the basis of length and duration of exposure). These employees shall be offered medical exams by a licensed physician without cost to the employee and offered other appropriate medical tests free of charge. The surveillance program will include:

- Initial examinations, including work history, medical history, physical examination, history of family. Specific tests may be required.

- Periodic examinations will be required at specific intervals determined in the individual rulemaking.

- Medical examinations will be given upon termination of work.

- Additional examinations may be required if certain symptoms appear.

The physician must be supplied with a copy of the standard and information regarding the employee's work surroundings. The physlctan must glve a written opinion to the employer, stating whether the employee has any condition which places him at "increased risk of material impairment" to health as a result of exposure. The employee shall be provided with a copy of this opinion by the employer. The licensed physician may be the company physician. There is still some controversy over this point.

Clearly, these requirements will in many cases require much more sophisticated programs. Many companies are turning 
to computerized surveillance to help them achieve compliance. Such compliance is likely to be a costly undertaking, particularly for such facilities as DOE plants located in remote Western sites near the coal supply.

n) Employee Information and Training

A program to cover this requirement will provide information from the final standard, description and use of respirators and the medical surveillance program, the engineering and work practices and likely situations of exposure. The employer may be required to provide all training materials to OSHA. Employees requiring training will be designated.

o) Signs and Labels

Where a potential carcinogen may be present or where exposures exceed action levels, the employer shall post signs stating: DANGER (NAME OF SUBSTANCE) CANCER HAZARD, AUTHORIZED PERSONNEL ONLY. Where exposures exceed the PEL, the sign must also state: "Respirator Required" Containers of, and products containing the potential carcinogen shall be labeled DANGER, CONTAINS (NAME), CANCER HAZARD.

These requirements are extensive and could clearly require much additional work. One item of concern here is that some contractors may refuse to handle containers labeled "Cancer Hazard". This situation may eventually necessitate some additional training or educational program and at the least may be expected to cause some minor delays.

\section{p) Recordkeeping}

Records must be kept of all required monitoring, including dates, number and duration of each sample, a description of the sampling procedure and the analytical techniques used. Names and social security numbers of monitored employees must be kept. The period. for which these records must be kept by the employer (preceeding a transfer to OSHA) will be specified in the standard.

Records of medical surveillance, copies of physicians' written opinions, copies of employee's work histories, and any complaints must be kept for a specified time period. All records must be made available on request to OSHA or the affected employee or designated representative. Records must be transferred to the successor or to OSHA in the case of an employer ceasing to do business.

Again, the extensive nature of these requirements makes computer assistance in compliance almost a necessity. Of further note is the probability that similar records may be required in the foreseeable future for all employees regardless of what chemicals they work with.

q) Observation of Monitoring

Employees or their representatives may observe monitoring procedures, and are entitled to receive an explanation of proce- 
dures, see individual steps taken, and record results obtained. They must be provided with protective clothing and equipment during observation, where necessary.

\section{Summary}

Each of these 17 major concerns will be addressed in the final standard for each chemical regulated. If any of the concerns are not addressed in the requirements of a particular standard, OSHA must justify the reasons for omission. This is an issue that may be debated during.individual rulemaking. The model standard is based on three principles which cannot be changed or modified without amending the rule. They will always be present in every final standard. They are:

- Worker exposure to Category I Potential Carcinogens will be reduced to the "lowest feasible level".

- Permissible exposure levels will be achieved primarily through engineering and work practice controls.

- Medical examinations and personal protective equipment required by individual standards will be provided at no cost to the employee.

Clearly, the principle implication to DOE of the model standard is that a major industrial hygiene and systems engineering effort will be required to address the questions of feasibility of engineering versus work practice controls. Unavoidably, extra costs will be involved 
Comparison: OSHA Model Regulations

and

FE OSH Manual Standards for Carcinogens

Following is a listing of all requirements of the OSHA model regulations that either differ from or are not included in the FE Programs OSH manual.

Permissible Exposure Limits Provisions

- Inhalation exposure shall be measured as an eight hour time weighted average. The limit is to be set at the "lowest feasible level".

- Where the Secretary requires a substitute to be used, the Secretary shall consider availability, practicability, relative degree of hazard and economic consequences.

- Limits for dermal and eye exposure will be set on a case-bycase basis.

\section{Notiflcation of Use and Emergencies}

Within 30 days after promulgation of a standard or after introduction of the substance in the workplace, every employer using the substance must report to the OSHA Area Office the location of the worksite and an estimate of employees exposed.

Emergencies are to be reported within a specified number of hours, or during the first federal working day after to the OSHA Area Office. Upon request, the employer must also furnish written information regarding employee exposure and measures taken to prevent recurrences.

\section{Exposure Monitoring}

- Exposure is that which would occur if the employee were not wearing a respirator.

- Provisions for initial and routine monitoring are covered in the $\mathrm{FE}$ manual.

- Additional monitoring may be required if there is a process, production, control or personnel change.

- Within a specified time period as appropriate, the employer must notify each employee in writing of the results of monitoring which represent his exposure.

- When the exposure has exceeded permissible limits, the notice must include that information, as wel1 as a description of corrective action being taken. 
Accuracy of Measurement

Requirements to be set case-by-case.

Regulated Areas

These provisions are similar to those in the FE manual.

Methods of Compliance.

Engineering and Work Practice Controls

Engineering controls are to be implemented even if they will not be sufficient to reduce exposures to the permissible limits, except to the extent the employer establishes that such controls are not feasible.

Compliance Program

The employer must establish a written program to reduce exposures to permissible limits. This requirement is partially covered in the FE manual (page 1-1, paragraph 3a). Further requirements for the plan are:

(1) a description of each operation resulting in employee exposure;

(2) engineering plans or other studies contemplated or used;

(3) a report of technology under consideration;

(4) detailed schedule for the implementation of controls;

(5) other relevant information.

Plans are to be submitted, on request, to the Assistant Secretary and the Director, and are to be made available at the worksite.

Respiratory Protection

Compliance within permissible exposure limits may not be achieved by use of respirators except:

(1) during the time period necessary to install controls;

(2) in operations in which the employer establishes that controls are not feasible;

(3) in situations where feasible controls are not sufficient;

(4) in emergencies.

Other Requirements are:

- respirators as well as other required protective equipment and clothing are required to be provided at no cost to the employee; 
- respirators used must be from among those approved by NIOSH under 30 CFR Part II (The FE manual references the NIOSH Respiratory Protection Guide) (VI-9);

- employees who wear respirators must be allowed to wash their face and respirator face piece, to prevent skin irritation;

- employer shall assure proper respirator fit (requirements for fit-testing to be indicated as appropriate).

Emergencies

A written plan must be developed for emergency situations.

Alerting Employees

Where there is a possibility of employee exposure due to an emergency, a general alarm must be installed to promptly alert employees.

Evacuation

Procedures are covered in the FE manual.

\section{Protective Clothing and Equipment}

Also covered in the $F E$ manual.

\section{Housekeeping}

The housekeeping program must include:

- scheduling of routine housekeeping;

- periodic cleaning of dust collection systems;

- provision for assigning personnel to housekeeping procedures;

- provisions for informing employees: about the housekeeping program.

\section{Waste Disposal}

Labeling provisions are covered in the FE manual. (Specific disposal methods are to be implemented as appropriate.)

Provisions regarding Hygiene facilities and practices, Change rooms and Showers are similar to those in the FE manual, except that 29 CFR 1910.141 is specifically noted as the guideline that must be complied with.

\section{Lunchrooms.}

Whenever food or beverages are consumed in the workplace, the employer must provide facilities that have a temperature: controlled, positive pressure, filtcrcd air supply and are readlly accessible to exposed employees. 


\section{Medical Surveillance}

General Provisions are essentially the same as in the FE manual.

Initial Examinations

Initial examinations should include at least the following: a work history, a medical history and physical examination with direct emphasis towards the organs or systems likely to be affected and must include personal and family history of the employee.

\section{Periodic Examinations}

Provisions are the same as in the FE manual except that an employer must make the prescribed physical exam available to employees upon termination if they have not already had such an exam.

\section{Additional Examinations}

Additional examinations are to be provided if the employee develops any signs or symptoms of exposure to the hazardous substance in question.

\section{Information Provided to the Physician}

Employer must provide:

- a copy of the OSHA standard and appendices;

- a description of the employee's duties as they relate to exposure;

- the employee's representative exposure level (or anticipated level for pre-placement exams);

- description of any personal protective equipment being used;

- names and addresses of physicians who previously provided medical examinations to the employee under sponsorship of the employer.

\section{Physician's Written Opinion}

The written opinion to be obtained by the employer is to include:

- the physician's certification that he has received all the above information and has performed all appropriate examinations and tests;

- the physician's opinion as to whether the employee has any condition which would place him/her at an increased risk due to exposure to substance in question;

- any recommendations regarding l1mits of exposure, use of protective clothing and equipment; 
- a statement that the employee has been informed by the physician of the results of the exam;

- the employer must instruct the physician not to reveal in the written opinion specific findings that are not related to occupational exposure;

- the employer must provide a copy of the written opinion to the employee.

\section{Employee Training Program}

Provisions are similar, but some of the following information may be required to be provided as appropriate:

- the information contained in the Appendices to the OSHA Standard;

- purpose, proper use and limitations of respirators;

- engineering and work practice controls, their function and the employee's relationship thereto;

- a review of the OSHA standard.

\section{Access to Training Materials}

The OSHA standard and its Appendices must be readily available. The employer must provide on request all materials relating to employee information and training to the Assistant Secretary and the Director.

\section{Signs}

- Must bear the legend:

DANGER

(Appropriate trade or common name)

CANCER HAZARD

AUTHORIZED PERSONNEL ONLY

- Must be illuminated and cleaned as necessary.

- Where airborne concentrations exceed permissible exposure levels, signs must also read: "Respirator Required".

Labe1s

Labels must remain affixed when the substance or products containing the substance are distributed. Labels must read:

DANGER

CONTAINS

CANCER HAZARD 


\section{Recordkeeping}

\section{Exposure Monitoring}

Employer's record must include: the dates, number, duration and results of each sample taken; a description of the sample and the procedure and the analytical methods used; type of respiratory protection used, if any; name, social security number, and job classification of all employees monitored.

\section{Medical Surveillance}

The employer's record is to include: a copy of the physicians' written opinions; any employee's medical complaints related to exposure to the hazardous substance; a copy of the information provided to the physician; a copy of the employee's work history.

\section{Availability}

All required records must be available upon request to the Assistant Secretary and the Director. Employee exposure measurement records, and medical records, are to be made available upon request to the employee, former employee, or designated representative.

\section{Transfer of Records}

Whenever the employer ceases to do business, the sucessor employer shall receive and retain all records. When there is no successor employer, the records shall be transmitted to the Director. At the expiration of the retention period, records are to be transmitted by the employer to the Director.

\section{Observation Procedures}

The provision allowing employees or their representatives to observe monitoring procedures are equivalent to those in the FE manual; with the additions that employers must provide the observer with protective clothing and equipment.

Also, without interfering with the monitoring, the observers are entitled to receive an explanation of the procedures, observe all steps, and record the results. 
Attachment I

KNOWN CARCINOGENS

IN COAL GASIFICATION/LIOUEFACTION

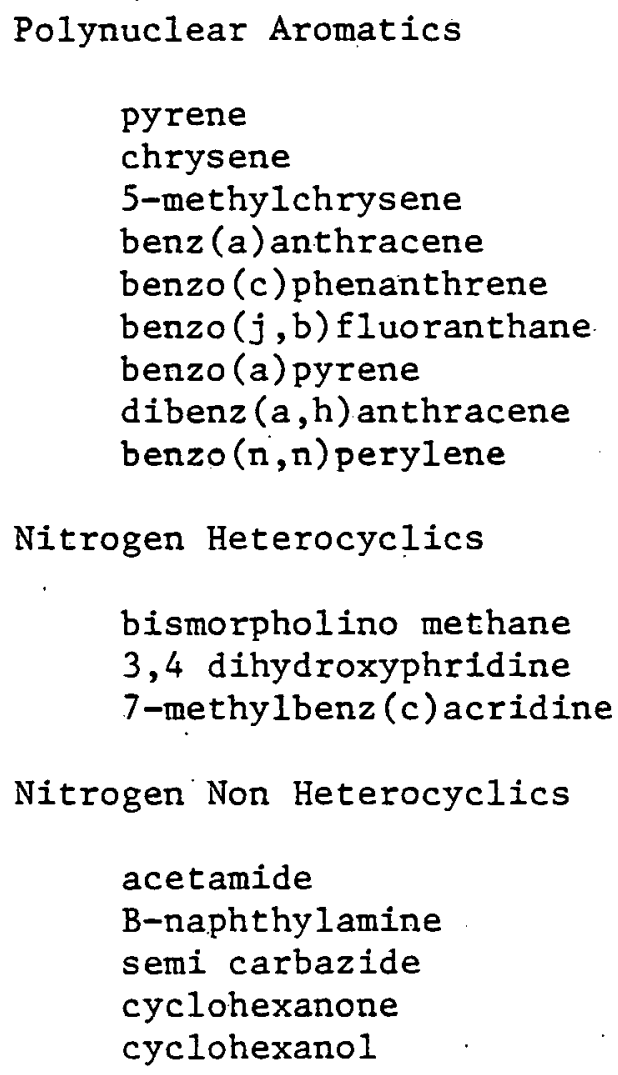

Nitrogen Heterocyclics

bismorpholino methane

3,4 dihydroxyphridine

7-methylbenz (c) acridine

Nitrogen Non Heterocyclics

acetamide

B-naphthylamine

semi carbazide

cyclohexanone

cyclohexanol

Benzene

Metals. (in flyash)

arsenic

beryllium

cadmium

chrome

culvalt

iron

lead

nickel

mercury

selenium 


\section{SUSPECTED CARCINOGENS}

IN COAL GASIFICATION/LIQUEFACTION

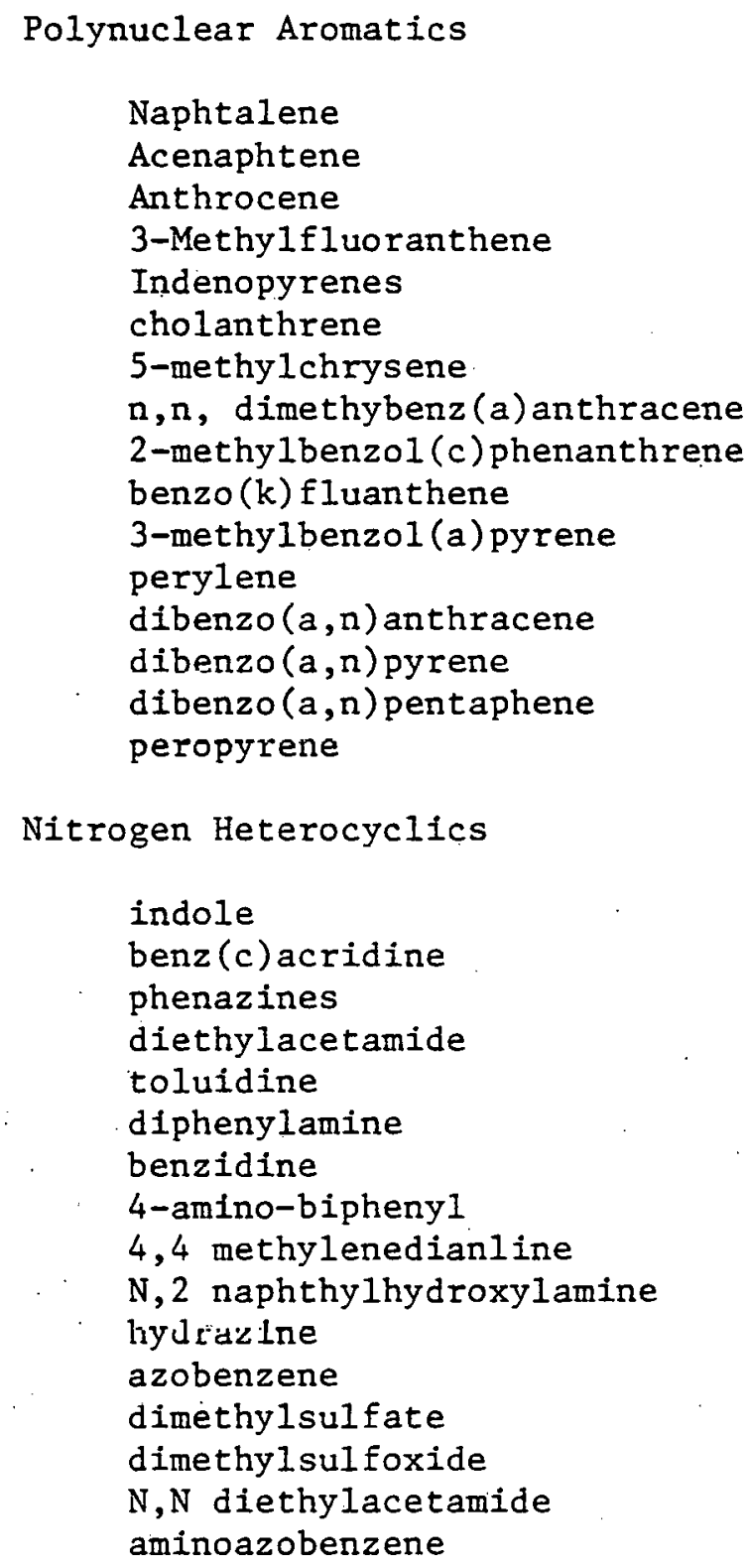

Phenols

phenol

0-chlorophenol

xylenol 
Carboxylic Acids

anthronilic acid

quinones

acetalhyde

Others

dioxane

ethanol

ethylene glycol 


\title{
REFERENCES
}

\author{
Health and Environmental Effects of Coal Technologies \\ Mitre Corporation \\ August 1979 \\ Carcinogens Relating to Coal Conversion Processes \\ ERDA \\ June 1976 \\ Publication FE 2213-1 \\ Coal Conversion Processes, Potential Carcinogenic Risk \\ March 1976 \\ Interior Department \\ Publication 271 A \\ Suspected Carcinogens \\ NIOSH, 2nd Edition \\ HEW Publication No. NIOSH 77-149
}


Attachment II

GENERAL INDUSTRY STANDARDS

AND INTERPRETATIONS 


\section{General Industry \\ Standards and \\ Interpretations}

July, 1977

Change 10-April 24, 1980

U.S. Department of Labor

Ray Marshall, Secretary

Occupational Safety and Health Administration

Eula Bingham, Assistant Secretary

Volume 1 OSHA 2077

For sale by the Superintendent of Documents, U.S. Government Printing Office Washington, D.C. 20402 


\section{GENERAL}

\section{$1990.101-S C O P E$}

This Part establishes criteria and procedures for the identification, classification, and regulation of potential occupational carcinogens found in each workplace in the United States regulated by the Occupational Safety and Health Act of 1970 (the Act). The procedures contained in this Part supplement the procedural regulations in other parts of this Chapter. In the event of a conflict, the procedures contained in this Part shall govern the identification, classification, and regulation of potential occupational carcinogens. This Part may be referred to as "The OSHA Cancer Policy:"

\subsection{2-PURPOSE}

The Act provides, among other things, that "the Secretary, in promulgating standards dealing with toxic materials or harmful physical agents under this subsection, shall set the standard which most adequately assures, to the extent feasible, on the basis of the best available evidence, that no employee will suffer material impairment of health of functional capacity even if such employee has regular exposure to the haz. ard dealt with by such standard for the period of his or her working life. Development of standards under this subsection shall be based upon research, demonstrations, experiments, and such other information as may be appropriate. In addi- tion to the attainment of the highest degree of health and safety protection for the employee, other considerations shall be the latest available scientific data in the field, the feasibility of the standards, and experience gained under this and other health and safety laws. Whenever practicable, the standard promulgated shall be expressed in terms of objective criteria and of the performance desired" (section 6(b)(5)). It is the purpose of the regulations of this Part to carry out the intent of the Act with respect to the identification, classification, and regulation of potential occupa. tional carcinogens.

\subsection{3-DEFINITIONS}

Terms used in this Part shall have the meanings set forth in the Act. In addition, as used in this Part, the following terms shall have the meanings set forth below:

"Act" means the Occupational Safety and Health Act of 1970 (Pub. L. 91-596, 84 Stat. 1590 et seg., 29 U.S.C. 551 et seq.).

"Administrator of EPA" means the Admini- strator of the United States Environmental Protection Agency, or designee.

"Chairperson of CPSC" means the Chairman of the United States Consumer Product Safety Commission, or designee.

"Commissioner of FDA" means the Commissioner of the Food and Drug Administration, 
'Jnited States Department of Health and Human iervices, or designee.

"Director of NCI" means the Director of the National Cancer Institute, United States Department of Health and Human Services, or designee.

"Director of NIEHS" means the Director of the National Institute of Environmental Health Sciences, United States Department of Health and Human Services, or designee.

"Director of NIOSH" means the Director of the National Institute for Occupational Safety and Health, United States Department of Health and Human Services, or designee.

"Secretary of HHS" means the Secretary of the United States Department of Health and Human Services, or designee.

"Mutagenesis" means the induction of heritable changes in the genetic material of either somatic or germinal cells.
"Positive results in short-term tests" means positive results in assays for two or more of the following types of effect: (1) the induction of DNA damage and/or repair; (2) mutagenesis in bacteria, yeast, Neurospora or Drosophila melanogaster; (3) mutagenesis in mammalian somatic cells; (4) mutagenesis in mammalian germinal cells; or (5) neoplastic transformation of mammalian cells in culture.

"Potential occupational carcinogen" means any substance, or combination or mixture of sub. stances, which causes an increased incidence of benign and/or malignant neoplasms, or a substantial decrease in the latency period between exposure and onset of neoplasms in humans or in one or more experimental mammalian species as the result of any oral, respiratory or dermal exposure, or any other exposure which results in the induction of tumors at a site other than the site of administration. This definition also includes any substance which is metabolized into one or more potential occupational carcinogens by mammals.

\subsection{4-SCIENTIFIC REVIEW PANEL}

(a) General. At any time, the Secretary may request the Director of NCI, the Director of NIEHS and/or the Director of NIOSH to convene a scientific review panel ("the panel") to provide recommendations to the Secretary in the identification, classification, or regulation of any poten. tial occupational carcinogen.

(b) Membership. The panel will consist of individuals chosen by the respective Director(s). The panel will consist of individuals who are appropriately qualified in the disciplines relevant to the issues to be considered, and who are employed by the United States. The panel does not constitute an advisory committee within the meaning of sections $6(\mathrm{~b})$ or $7(\mathrm{~b})$ of the Act, or the Federal Advisory Commitlee Act (Pub. L. 92-463, 86 Stat. 770). (c) Report. The Secretary shall request that the panel submit a report of its evaluation within ninety (90) days after the appointment of the members of the panel. The Secretary shall place a copy of the report in the record of any relevant rulemaking undertaken pursuant to this Part and allow an appropriate time for public review and comment. If a panel is not established or fails to file a timely report, or if the Secretary determines that it is necessary to proceed without waiting for the panel's report, the Secretary may proceed in making any determination without such report.

(d) Other oid and ossistance. Nothing herein precludes the Secretary from obtaining advice or other aid from any person or organization including NCI, NIEHS, and NIOSH. 
The Secretary may appoint an Advisory Committee, pursuant to sections $6(\mathrm{~b})$ and 7 of the Act, and 29 CFR Part 1912, concerning any potential occupational carcinogen. The Secretary shall require the Advisory Committee to submit its recommendations to assist the Secretary in standard setting no later than ninety (90) days from the date of the Advisory Committee's appointment, unless extended by the Secretary for exceptional circumstances. If an Advisory Committee fails to file a timely report, the Secretary may proceed in standard setting activities without such a report.

\subsection{6 - AMENDMENTS TO THIS POLICY}

\section{(a) Initation of review of this policy. -}

(1) Secretary's request. No later than every three (3) years from the effective date of this Part, or from the last general review, the Secretary shall request the Director of NCI, the Director of NIEHS and/or the Director of NIOSH, to review this Part and render their opinions on whether significant scientific or technical advances made since the effective date of this Part warrant any amendment to this Part. The request shall ask that the answer be provided to the Secretary within one hun. dred twenty (120) days.

(2) Recommendations by the institutes. At any time, the Director of NCI, the Director of NIEHS and/or the Director of NIOSH may submit recommendatiuons to the Secretary for amendments to this Part whenever any of them believes that scientific or technical advances justify such amendments.

\section{(3) Petitions from the public.}

(i) Any interested person may petition the Secretary concerning amendments to this Part based upon substantial new issues or substantial new evidence.

(ii) For the purposes of this Part, substantial new evidence is evidence which differs significantly from that presented in establishing this Part, including amendments. (iii) For the purposes of this Part, substan. tial new issues are issues which differ significantly from those upon which the Secretary has reached a conclusion in the rulemaking establishing this Part (including the conclu. sions reached in the preamble.)

(iv) Each petition to amend this part shall contain at least the following information:

(a) Namo and address of petitinner;

(b) The provisions which the petitioner believes are inappropriate;

(i) All data, views und argumonte roliod upon by the petitioner; and

(d) A detailed statement and analysis as to why the petitioner believes that the data, views and arguments presented by petitioner:

(i) Constitute substantial new issues or substantial new evidence; and

(ii) Are so significant as to warrant amendment of this Part.

(b) Response to recommendations and petitions.

(1) By the institutes. Whenever any Director recommends an amendment ot this part, the 
Secretary shall, within one hundred twenty (120) days after receipt of the recommendation. publish in the Federal Register, a notice which

(i) states the reasons why the Secretary has determined not to commence a rulemaking proceeding to amend this Part, in whole or in part, at that time; or

(ii) commences a rulemaking proceeding to consider amending this Part accordingly; or

(iii) appoints an Advisory Committee as provided for by 1990.105 of this Part and sections $6(\mathrm{~b})$ and 7 of the Act.

(2) By the public. Within ninety $(90)$ days, or as soon thereafter as possible, after receipt of a petition pursuant to section 1990.106 (a)(3), the Secretary shall:

(i) refer the petition to the Director of NCI, the Director of NIEHS and/or the Director of NIOSH, in which case the provisions of $1990.106(a)$ and (b)(1) are applicable; or

(ii) appoint an advisory committee;

(iii) deny the petition, briefly giving the reasons therefor: or

(iv) commence a rulemaking proceeding to consider amending this Part accordingly.

(3) On the Secretary's motion. At any time, the Secretary may, on his own motion, commence a rulemaking proceeding to amend this Part.

\section{THE OSHA CANCER POLICY}

\subsection{1-GENERAL STATEMENT OF REGULATORY POLICY}

(a) This Part establishes the criteria and procedures under which substances will be regulated by OSHA as potential occupational carcinogens. Although the conclusive identification of "carcinogens" is a complex matter "on the frontiers of science," (IUD v. Hodgson 499 F. 2d 467, 474 (D.C. Cir. 1974)), responsible health regulatory policy requires that criteria should be specified for the identification of substances which should be regulated as posing potential cancer risks to workers.

(b) The criteria established by this Part are based on an extensive review of scientific data and opinions. The Part proviles for amending these criteria in light of new scientific developments. Decisions as to whether any particular substance meets the criteria or not. will be consistent with the policies and procedures established by the Part and will be based upon scientific evaluation of the evidence on that substance.

(c) This Part applies to individual substances, groups of substances, or combinations or mix- tures of substances which may be found in workplaces in the United States. In individual rulemaking proceedings under this Part, the identity and range of substances and mixtures to be covered by the standard will be specified and the appropriateness of applying the avaliable evidence to the range of substances and mixtures proposed for regulation will be subject to scientific and policy review.

(d) Potential occupational carcinogens will be identified and classified on the basis of human epidemiological studies and/or experimental carcinogenesis bioassays in mammals. Positive results in short term tests will also be used as concordant evidence.

(e) Potential occupational carcinogens will be classified and regulated in accordance with the policy. The scientific evidence as to whether individual substances meet these criteria will be considered in individual rulemakings. The issues which may be considered in these rulemakings will be limited as specified herein. 
STANDARDS AND INTERPRETATIONS

(f) This policy provides for the classification of potential occupational carcinogens into two categories depending on the nature and extent of the available scientific evidence. The two categories of potential occupational carcinogens may be regulated differently.

(g) The policy establishes a procedure for setting priorities and making them public.

(h) Worker exposure to Category I Potential Carcinogens will be reduced to the lowest feasible level, primarily through the use of engineering and work practice controls. This is predicated in part upon the finding that no methods have been demonstrated for establishing exposure levels for carcinogens, acting singly or in combination, below which risks to exposed workers would be absent.

(i) Worker exposure to Category II Potential Carcinogens will be reduced as appropriate and consistent with the statutory requirements on a case-by-case basis in the rulemaking proceedings on individual substances. Any permissible exposure level so established shall be met primarily through engineering and work practice controls.

(i) The assessment of cancer risk to workers resulting from exposure to a potential occupational carcinogen will be made on the basis of available data. Because of the uncertainties and serious consequences to workers if the estimated risk is understated, cautious and prudent assumptions will be utilized to perform risk assessments. The form and content of the risk assessment will thus depend on the Secretary's judgment of the available data.

(k) Where the Secretary determines that one or more suitable substitutes exist for certain uses of Category I Potential Carcinogens that are less hazardous to humans, a no occupatlonal expusure level shall be set for those uses, to be achieved solely through the use of engineering and work practice controls to encourage substitution. In determining whether a substitute is suitable, the Secretary will consider the technulugical and economic feasibility of the introduction of the substitute, including its relative effectiveness and other relevant factors, such as regulatory requirements and the time needed for an orderly transition to the substitute.

\subsection{2-CLASSIFICATION OF POTENTIAL CARCINOGENS}

The following criteria for identification, classification and regulation of potential occupational carcinogens will be applied, unless the Secretary considers evidence under the provisions of $1990.143,1990.144$ and 1990.145 and determines that such evidence warrants an exception to these criteria.

(a) Category I Potential Carcinogens. A substance shall be identified, classified, and regulated as a Cat.egnry I Potential Carcinogen if, upon scientific evaluation, the Secretary determines liat the substance meets the definition of a potential occupational carcinogen in (i) humans, or (ii) in a single mammalian species in a long-term bioassay where the results are in concordance with some other scientifically evaluated evidence of a potential carcinogenic hazard, or (iii) in a single mammalian species in an adequately conducted long- term bioassay, in appropriate circumstances where the Becretary dotormines the requirement for concordance is not necessary. Evidence of concordance is any of the following: positive results for independent testing in the same or other species, positive results in short-term tests, or induction of tumors at injection or implantation sites.

(b) Category II Potential Carcinogens. A substance shall be identified, classified, and regulated as a Catcgory II Potential rarcinogen if, upon scientific evaluation, the Secretary determines that: (i) the substance meets the criteria set forth in $1990.112(a)$, but the evidence is found by the Secretary to be only "suggestive" or (ii) the substance meets the criteria set forth in $1990.112(\mathrm{a})$ in a single mammalian species with out evidence of concordance. 


\section{PRIORITY SETTING}

\subsection{1-CANDIDATE LIST OF POTENTIAL OCCUPATIONAL CARCINOGENS}

(a) Contents. The Secretary shall prepare a list of substances (the "Candidate List") which are reported to be present in any American workplace and which, on the basis of a brief scientific review of available data, may be considered candidates for further scientific review and possible regulation as Category I Potential Carcinogens or Category II Potential Carcinogens. For the purposes of this paragraph, "available data" means:

(1) The data submitted by any person;

(2) Any data referred to by the Secretary of HHS or by the Director of NIOSH, either in the latest list entitled "Suspected Carcinogens" or any other communicaton;

(3) Literature referred to in U.S. Public Health Service, Publication No. 149;

(4) Data summarized and reviewed in Monographs of the International Agency for Research on Cancer (IARC) of the . World Health Organization;

(5) The Toxic Substances Control Act Inventory of Chemical Substances, published by the Community Mental Health Centers Extension Act of 1978, sec. 404(a)(9), 42 U.S.C. sec. 285. (b) Tentative classification. The Secretary may tentatively designate substances on the Candidate List as candidates for classification as Category I Potential Carcinogens or as Category II Potential Carcinogens, or may list substances without a tentative designation, based on the brief scientific review of available data for the purpose of initiating a more extensive scientific review.

(c) No legal rights established. The inclusion or exclusion of any substance from the Candidate List shall not be subject to judicial review nor be the basis of any legal action, nor shall the exclusion of any substance from the list prevent the regulation of that substance as a potential occupational carcinogen. The inclusion of a substance on the Candidate List and its possible tentative designation as a Category I Potential Carcinogen or a Category II Potential Carcinogen therein do not reflect a final scientific determination that the substance is, in fact, a Category I Potential Carcinogen or a Category II Potential Carcinogen. It is a policy determination based on the brief scientific review that the Secretary should conduct a thorough review of all relevant scientific data concerning the substance.

\subsection{2 - RESPONSE TO PETITIONS}

Whenever the Secretary receives any information submitted in writing by any interested person concerning the inclusion or omission of any substance from the Candidate List, the Secretary shall briefly review the information and any other available data, as defined in 1990.121(a). The results of the Secretary's review shall be transmitted to the petitioner, together with a short statement of the Secretary's reasons therefor, and made public upon request. 


\subsection{1-PRIORITY LISTS FOR REGULATING POTENTIAL OCCUPATIONAL CARCINOGENS}

The Secretary shall establish two priority lists for regulating potential occupational carcinogens. One list should include approximately ten (10) candidates for rulemaking as Category I Potential Carcinogens; the other approximately ten (10) candidates for rulemaking as Category II Potential Carcinogens. The order of placement of substances on these lists will not reflect the Secretary's determination of the exact order in which these substances should be regulated in rulemaking proceedings but rather a policy determination that the Secretary plans to address some or all of these substances prior to pro- ceeding with a thorough scientific review of data concerning other substances on the Candidate List. The inclusion or exclusion of any substance on these lists shall not be subject to judicial review or be the basis for any legal action. The Secretary may regulate a potential occupational carcinogen which has not been placed on these lists. The inclusion of a substance on either of these lists does not reflect a final scientific determination that the substance is, in fact, a Category I Potential Carcinogen or a Category II Potential Carcinogen.

\subsection{FACTORS TO BE CONSIDERED}

(a) The setting of priorities is a complex matter which requires subjective and policy judgments. It is not appropriate to establish a rigid formula or to assign predetermined weight to each factor. The identification of some of the elements is to guide the OSHA staff and inform the public on the development of priorities. It is not intended to create any legal rights with respect to the setting of priorities.

(b) Some factors which may be taken into account in setting priorities for regulating potential occupational carcinogens, when such data are available, are:

(1) The estimated number of workers exposed;

(2) The estimated levels of human exposure;

(3) The levels of exposure to the substance which have been reported to cause an increased incidence of neoplasms in exposed humans, animals or both;
(4) The extent to which regulatory action could reduce not only risks of contracting cancer but also other occupational and environmental health hazards;

(5) Whether the molecular structure of the substance is similar to the molecular structure of another substance which meets the definı. tion of a potential occupational carcinogen;

(6) Whether there are substitutes iha. jos $t$ lower risk of cancer or other serious human health problems, or available evidence otherwise suggests that the social and economic costs of regulation would be small; and

(7) OSHA will also consider its responsibilities for dealing with other health and safety hazards and will consider the acions being taken or planned by other governmental agencies in dealing with the same or similar health and safety hazards. 
(a) The Secretary shall publish the Candidate List in the Federal Register at least annually.

(b) The Secretary shall publish the Priority Lists in the Federal Register at least every six months and may seek public comment thereon. (c) The Secretary may periodically publish in the Federal Register a notice requesting information concerning the classification and establishment of priorities for substances on the Candidate List together with a brief statement describing the type of information being sought.

\section{REGULATION OF POTENTIAL OCCUPATIONAL CARCINOGENS}

\subsection{1-ADVANCE NOTICE OF PROPOSED RULEMAKING}

(a) Within thirty (30) days after OSHA initiates a study concerning the economic and/or technological feasibility of specific standards that might be applied in the regulation of a potential occupational carcinogen, the Secretary will normally publish, in the Federal Register, a notice which includes at least the following:

(1) The name of the substance(s).

(2) The scope of the study, including where possible, (i) affected industries, (ii) levels of exposure being studied, (iii) the anticipated completion date of the study;

(3) A brief summary of the available data on health effects; $\because ?$

(4) An estimate of when the Secretary anticipates the issuance of a proposal;
(5) An invitation to interested parties to provide relevant information;

(6) A statement that persons wishing to provide OSHA with their own study shnuld com plete it within 30 days after the anticipated proposal date; and

(7) A statement of the procedural requirements that must be met before substantial new issues or substantial new evidence will be con: sidered in the proceeding pursuant to $\xi$. 1990.145 .

(b) Where the Secretary determines to discontinue a feasibility study, the Secretary should publish, within 30 days, a notice in the Federal Register so indicating.

\subsection{2-INITIATION OF A RULEMAKING}

Where the Secretary decides to regulate a potential occupational carcinogen, the Secretary shall initiate a rulemaking proceeding in accordance with one of the following procedures, as appropriate. (a) Notice of proposed rulemakings (Sec. tion $6(\mathrm{~b})$ of the Act)

(1) General. The Secretary may issue a notice of proposed rulemaking in the Federal Regis- 
STANDARDS AND INTERPRETATIONS

ter, pursuant to Section 6(b) of the Act and Part 1911 of this Chapter. The notice shall provide for no more than a sixty (60) day comment period, and may provide for a hearing, which shall be scheduled for no later than one hundred (100) days after publication of the Notice of Proposed Rulemaking. The commencement of the hearing may be postponed once, for no more than thirty (30) days, for good cause shown.

(2) Provisions of the proposed standard for Category I Potential Carcinogens. Whenever the Secretary issues a notice of proposed rulemaking to regulate a substance as a Category I Potential Carrinngen:

(i) The propsoed standard shall contain at least provisions for scope and application, definitions, notification of use, a permissable exposure limit, monitoring, regulated areas, methods of compliance including the development of a compliance plan, respiratory pro. tection, protective clothing and equipment, housekeeping, waste disposal, hygiene facilities, medical surveillance, employee information and training, signs and labels; recordkeeping, and employee observation of monitoring as set forth in $\S 1990.151$, unless the Secretary explains why any or all such provisions are not appropriate;

(ii) The model standard set forth in $\S$ 1990.151 shall be used as a guideline, and

(iii) The permissible exposure limit shall be set be set as low as feasible, to be achieved primarily through engineering and work practice controls, except that if a suitable substitute is available for one or more uses, no occupational exposure shall be permitted for those uses.

(3) Provisions of the proposed standard for Category II Potential Corcinogens. Whenever the Secretary issues a Notice of Proposed Rulemaking to regulate a substance as a Category II Potential Carcinogen:

(i) The proposed standard shall contain at least provisions for scope and application, definitions, notification of use, monitoring, respiratory protection, protective clothing and equipment, housekeeping, waste dispos- al, medical surveillance, employee informa. tion and training, recordkeeping and employee observation of monitoring as set forth in $\S 1990.151$, unless the Secretary explains why any or all such provisions are not appropriate; and

(ii) The model standard set forth in $\S$ 1990.151 shall be used as a guideline; and

(iii) Worker exposure to Category II Potential Carcinogens will be reduced as appropriate and consistant with the statutory requirements on a case-by-case basis in the individual rulemaking proceedings. Any permissible exposure level so established shall be met primarlly through engineering and work practice controls.

(b) Emergency temporary standards. (Soc. tion $6(c)$ of the Act).

(1) Generol. The Secretary may issue an Emergency Temporary Standard (ETS) for a Category I Potential Carcinogen in accordance with section 6(c) of the Act.

(2) Grove Donger. Employee exposure to Category I Potential Carcinogens constitutes a "grave danger" within the meaning of section 6 (c) of the Act.

\section{(3) Provisions of the ETS.}

(i) The ETS shall contain at least provisions for scope and application, definitions, notification of use, a permissible exposure limit, muniluring, methods of complianoe including the development of a compliance plan, respiratory protection, protective clothing and equipment, housekeeping, waste disposal, medical surveillance, employee information and trajning, signs and labels, recordkeeping and employee observation of monitoring unless the Secretary explains why any or all such provisions are not appropriate.

(ii) The model standard set forth in 1990.152 shall be used as a guideline.

(iii) The permissible exposure limit shall be set as low as feasible through any practicable combination of engineering controls, work practice controls and respiratory protection. 


\subsection{3-GENERAL PROVISIONS FOR THE USE OF HUMAN AND ANIMAL DATA}

Human and animal data which are scientifically evaluated to be positive evidence for carcinogenicity shall be uniformly relied upon for the identification of potential occupational carcinogens. Arguments challenging the following provisions or their application to specific substances will be considered in individual rulemaking proceedings only if the evidence presented in support of the arguments meets the criteria for consideration specified in $\S 1990.144$ or $\S 1990.145$.

(a) Positive humon studies. Positive results obtained in one or more human epidemiologic studies will be used to establish the qualitative inference of carcinogenic hazards to workers.

(b) Positive animal studies. Positive results obtained in one or more experimental studies conducted in one or more mammalian species will be used to establish the qualitative inference of carcinogenic hazard to workers. Arguments that positive results obtained in mammalian species should not be relied upon will be considered only if evidence is presented which meets the criteria for consideration specified in $\S 1990.144(\mathrm{c})$ or 1990.144(f).

(c) Non-positive human studies. Positive results in human or mammalian studies generally will be used for the qualitative identification of potential occupational carcinogens, even where non-positive results from human studies exist. Such nonpositive results will be considered by the Secretary only if the studies or results meet the criteria set forth in $\S 1990.144(a)$.

(d) Non-positive animal studies. Positive results in one or more mammalian studies will be used for the qualitative identification of potential occupational carcinogens, even where non-positive studies exist in other mammalian species. Where non-positive and positive results exist in studies in the same species, the non-positive results will be evaluated.

(e) Spontaneous tumors. Positive results in human or mammalian studies for the induction or acceleration of induction of tumors of a type which occurs "spontaneously" in unexposed indi- viduals will be used for the qualitative identification of potential occupational carcinogens.

\section{(f) Routes of exposure.}

(1) Positive results in studies in which mammals are exposed via the oral, respiratory or dermal routes will be used for the qualitative identification of potential occupational carcinogens, whether tumors are induced at the site of application or distant sites.

(2) Positive results in studies in which mammals are exposed via any route of exposure and in which tumors are induced at sites distant from the site of administration will be used for the qualitative identification of potential occupational carcinogens.

(3)

(1) Positive results in mammalian studies in which tumors are induced only at the site of administration, in which a substance or mixture of substances is administered by routes other than oral, respiratory or dermal, will be used as "concordant" evidence that a substance is a potential occupational carcinogen.

(ii) Arguments that such studies should not be relied upon will be considered only if evidence which meets the criteria set forth in $\S$ $1990.144(\mathrm{~b})$ is provided.

(g) Use of high doses in onimal testing. Positive results for carcinogenicity obtained in mammals exposed to high doses of a substance will be used to establish the qualitative inference of carcinogenic hazard to workers. Arguments that such studies should not be relied upon will be considered only if evidence which meets the criteria set forth in $\S 1990.144$ (d) is provided.

(h) "Threshold" or "No-effect" Levels. No determination will be made that a "threshold" or "noeffect" level of exposure can be established for a human population exposed to carcinogens in general, or to any specific substance. 
STANDARDS AND INTERPRETATIONS

(i) Benign tumors. Results based on the induction of benign or malignant tumors, or both, will be used to establish a qualitative inference of carcinogenic hazard to workers. Arguments that substances that induce benign tumors do not present a carcinogenic risk to. workers will be considered only if evidence that meets the criteria set forth in $\S 1990.144(e)$ is provided.

(i) Statistical evaluation. Statistical evaluation will be used in the determination of whether results in human, animal or short-term studies provide positive evidence for carcinogenicity, but will not be the exclusive means for such evaluation. (k) Carcinogenicity of metabolites. A substance which is metabolized by mammals to yield one or more potential occupational carcinogens will itself be identified and classified as a potential occupational carcinogen, whether or not there is direct evidence that it induces tumors in humans or experimental animals. Evidence for such metabolism will normally be derived from in vivo studies in mammals. In appropriate circumstances, evidence may be derived from in vitro studies of mammalian tissues or fractions thereof. Arguments that evidence from in vivo metabolic studies in mammals is not relevant to the inference of carcinogenic hazard to humans will be considered only if such evidence meets the crileria set forth in $\S 1990.144(0)$.

\subsection{4-CRITERIA FOR CONSIDERATION OF ARGUMENTS ON CERTAIN ISSUES}

Arguments on the following issues will be considered by the Secretary in identifying, classifying or regulating any substance pursuant to this Part, if evidence for the specific substance subject to the rulemaking conforms to the following criteria. Such arguments and evidence will be evaluated based upon scientific and policy judg. ments.

(a) Non-positive results obtained in human epidemlologic studies. Non-positive results obtained in human epidemlologic studiès regard ing the substance subject to the rulemaking or to a similar or closely related substance will be considered by the Secretary only if they meet the following criteria:

\footnotetext{
Criteria. (i) The epidemiologic study involved at least 20 years' exposure of a group of subjects to the substance and at least 30 years' observation of the subjects after initial exposure:
}

(ii) Documented rcasons are provided for predicting the site(s) at which the substance would induce cancer if it were carcinogenic in humans; and

(iii) The group of exposed subjects was large enough for an increase in cancer incidence of $50 \%$ above that in unexposed controls to have been detected at any of the predicted sites.

Arguments that non-positive results obtained in human epidemiologic studies should be used to establish numerical upper limits on potential risks to humans exposed to specific levels of a substance will be considered only if criteria (i) and (ii) are met and, in addition:

(iv) Specific data on the level of exposure of the group of workers are provided, based either on direct measurements made periodically throughout the period of exposure, or upon other data which provide reliable evidence of the mag. nitude of exposure.

(b) Tumors induced at site of administration. Arguments that tumore at the site nf administra. tion should not be considered will be considered only if:

(i) The route of administration is not oral, respiratory or dormal; and

(ii) Evidence is provided which establishes that induction of local tumors is related to the physical configuration or formulation of the material administered (e.g., crystalline form or dimensions of a sulid iuaterial, or matrix of an impreg. nated implant) and that tumors are not induced when the same material is administered in a different conflguraliuu us formula.

(c) Metabolic differences. Arguments that differences in metabolic profiles can be used to demonstrate that a chemical found positive in an experimental study in a mammalian species would pose no potential carcinogenic risk to 
exposed workers will be considered by the Secreary only if the evidence presented for the specif- substance subject to the rulemaking meets the following criteria:

Criteria. (i) A complete metabolic profile, including identities of trace metabolites, is presented for the experimental animal species;

(ii) A complete metabolic profile, including identities of trace metabolites, is available for a human population group representative of those who are occupationally exposed;

(iii) Documented evidence is provided for ascribing the carcinogenic activity of the substance in the test animal species to metabolite(s) produced oniy in that species and not in humans; and

(iv) Documented evidence is provided to show that other metabolites produced also in humans have been adequately tested and have not been shown to be carcinogenic.

(d) Use of high doses in animal testing. Arguments that positive results obtained in carcinogenesis bioassays with experimental animals subjected to high doses of a substance are not relevant to potential carcinogenic risks to exposed workers will be considered by the Secretary only if the evidence for the specific substance subject to the rulemaking meets the following criteria:

Criteria. (i) Documented evidence is presented to show that the substance in question is metabolized by the experimental animal species exposed at the dose levels used in the bioassay(s) to metabolic products which include one or more that are not produced in the same species at lower doses.

(ii) Documented evidence is presented to show that the metabolite(s) produced only at high doses in the experimental animal species are the ultimate carcinogen(s) and that the metabolites produced at low doses are not also carcinogenic; and

(iii) Documented evidence is presented to show that the metabolite(s) producod only at higlt loses in the experimental animal species are not produced in humans exposed to low doses. (e) Benign tumors. The Secretary will consider evidence that the substance subject to the rulemaking proceeding is capable only of inducing benign tumors in humans or experimental animals provided that the evidence for the specific substance meets the following criteria:

Criteria. (i) Data are available from at least two wellconducted bioassays in each of two species of mammals (or from equivalent evidence in more than two species);

(ii) Each of the bioassays to be considered has been conducted for the full lifetime of the experimental animals;

(iii) The relevant tissue slides are made available to OSHA or its designee and the diagnoses of the tumors as benign are made by at least one qualified pathologist who has personally examined each of the slides and who provides specific diagnostic criteria and descriptions; and

(iv) All of the induced tumors must be shown to belong to a type which is known not to progress to malignancy or to be at a benign stage when observed. In the latter case, data must be presented to show that multiple sections of the affected organ(s) were adequately examined to search for invasion of the tumor cells into adjacent tissue, and that multiple sections of other organs were adequately examined to search for tumor metastases.

(f) Indirect mechanisms. The Secretary will consider evidence that positive results obtained in a carcinogenesis bioassay with experimental animals are not relevant to a determination of a carcinogenic risk to exposed workers, if the evidence demonstrates that the mechanism by which the observed tumor incidence is effected is indirect and would not occur if humans were exposed. As examples, evidence will be considered that a substance causes a carcinogenic effect by augmenting caloric intake or that the carcinogenic effect from exposure to a substance is demonstrated to be the result of the presence of a carcinogenic virus and it is demnnstrated that, in either case, the effect would not take place in the absence of the particular carcinogenic virus or the augmented caloric intake.

\subsection{5-Consideration of substantial new issues or substantial new evidence}

(a) Substantial new issues. Notwithstanding any other provision of this Part, the Secretary will consider in a rulemaking proceeding on a specific substance any substantial new.issues upon which the Secretary did not reach a conclusion in the rulemaking proceeding(s) underlying this Part including conclusions presented in the preamble. 


\section{STANDARDS AND INTERPRETATIONS}

(b) Substantial new evidence. Nothwithstanding any other provision of this Part, the Secretary will consider in a rulemaking proceeding on a specific substance any arguments, data or views which he determines are based upon substantial new evidence which may warrant the amendment of one or more provisions of this Part. For the purposes of this Part, "substantial new evidence" is evidence directly relevant to any provision of this Part and is based upon data, views or arguments which differ significantly from those presented in establishing this Part, including amendments thereto.

\section{(c) Petitions for consideration of substan- tial new evidence.}

(1) Petition. Any interested person may file a written petition with the Secretary to consider "substantial new issues" or one or more "substantial new issues" which contains the information specified in paragraph $(c)(2)$ of this section. The Secretary shall treat such a petition as a request to amend this Part, as well as a petition to consider "substantial new evidence".

(2) Contents. Each petition for consideration of "substantial new evidence" or one or more "substantial new issues" shall contain at least the following information:

(i) Name and address of the petitioner;

(ii) All of the data, views and arguments that the petitioner would like the Secretary ton consider;

(iii) The provicion or provisions that petitioner believes are inappropriate or should be added to this Part in light of the new data, views, and arguments;

(iv) A statement which demonstrates that the data, views, and arguments relled upon by petitioners are directly relevant to the substance or class of substances that is the subject of a rulemaking or an Advance Notice of Proposed Rulemaking;

(v) A detailed statement and anylysis as to why the petitioner believes that the data, views, and arguments presented by the pet tioner:

(a) differ significantly from those presented in the proceeding(s) which establish this Part;

(b) are so substantial as to warrant amendment of this Part; and

(c) constitute a new issue or new evidence within the meaning of paragraphs (a) and (b) of this section.

\section{(3) Deadline for petitions.}

(i) Petitions which comply with paragraph (c) above, shall be filed in accurdance with the schedule set forth in the Advanced Notice of Proposed Rulemaking.

(ii) In extraordinary cases the Secretary may consider evidence submitted after the deadline if the petitioner establishes that the evidence rclied upon was not available and could not have reasonably been available in whole or substantial part by the deadline and that it is being submitted at the earliest possible time.

\section{(d) Secretary's response.}

(1) The Secretary shall respond to petitions under this paragraph in accordance with $\S$ 1990.106.

(2) Whenever the Secretary determines that the "substaulial new issuo" or the "suhstantial new evidence" submitted under this paragraph is sufficient to initiate a proceeding to amend this Part, the Secretary shall:

(i) Issue a notice to consider amendment to this Part and not proceed on the rulemaking concerning the individual substance until completion of the amendment proceeding; or

(ii) Issue a notice to consider amendment to this Part and consolidate it with the pro. ceeding on the individual substance. 


\subsection{6-ISSUES TO BE CONSIDERED IN THE RULEMAKING}

Except as provided in $\S 1990.145$, after issuance of the advance notice of rulemaking, the proceedings for individual substances under this Part shall be limited to consideration of the following issues:

(a) Whether the substance, group of substances or combination of substances subject to the proposed rulemaking is appropriately considered in a single proceeding;

(b) Whether the substance or group of substances subject to the rulemaking meets the definition of a potential occupational carcinogen set forth in $\S 1990.103$, including whether the scientific studies are reliable;

(c) Whether the available data can appropriately be applied to the substance, group of substances or combination of substances covered by the rulemaking;

(d) Whether information, data, and views that are submitted in accordance with $\S 1990.144$ are sufficient to warrant an exception to this Part;

(e) Whether the data, views and arguments that are submitted in accordance with $\S 1990.145$ are sufficient to warrant amendment of this Part;

(f) Whether the potential occupational carcinogen meets the criteria for a Category I Potential
Carcinogen or a Category II Potential Carcinogen.

(g) The environmental impact arising from regulation of the substance;

(h) Any issues required by statute or executive order;

(i) The determination of the lowest feasible level to control exposures to Category I Potential Carcinogens primarily through the use of engineering and work practice controls including technological and economic considerations;

(i) The determination of the appropriate employee exposure level, consistent with the Act's requirements for Category II Potential Carcinogens;

(k) Whether suitable substitutes are available for one or more us of Catgory I Potential Carcinogens and; if so, the no occupational exposure level to be achieved solely with engineering and work practice controls and other issues relevant to substitution; and

(I) Whether the provisions of the proposal and of $\S 1990.151$ and $\S 1990.152$ (model standards) are appropriate, except as limited by $\S 1990.142$ and whether additional regulatory provisions may be appropriate.

\subsection{7-FINAL ACTION}

(a) Within one hundred twenty (120) days from the last day of any hearing or ninety (90) days from the close of any post hearing comment period, whichever occurs first, the Secretary shall publish in the Federal Register:

(1) A final standard based upon the record in the proceeding; or

(2) A statement that no final standard will be issued, and the reasons therefor, or

(3) A statement that the Secretary intends to issue a final rule, but that he is unable to do so at the present time, including:

(i) The reasons therefor; and

(ii) The date by which the standard will be published, which may not exceed one hun- 
STANDARDS AND INTERPRETATIONS

dred twenty (120) days thereafter.

(iii) The Secretary may issue no more than one such notice, unless the Secretary determines that (a) new evidence which was unavailable during the rulemaking proceedings has just become available; (b) the evidence is so important that a final rule could not reasonably be issued without this evidence, and; $(c)$ the record is reopened for receipt of comments and/or a hearing on this evidence. This paragraph does not require the Secretary to consider any evidence which is submitted after the dates established for the submission of evidence.

(b) The failuro of the Serretary to comply with the required timeframes shall not be a basis to set aside any standard or to require the issuance of a new proposal on any individual substance.

(c) The final standard shall state whether the substance or group of substances subject to the rulemaking is classified as a Category I Potential Carcinogen or as a Category II Potential Carcinogen. If the classification differs from that in the notice of proposed rulemaking, the Secretary shall explain the reasons for the change in classification in the preamble to the final standard.

(d) If the substance is classified as a Category I Potential Carcinogen, the final standard shall conform to the provisions of section 1990.142 (a) (2)(iii). If the final standard contains other provisions that substantially differ from the proposec provisions, the Secretary shall explain the reasons for the changes in the preamble to the final standard.

(e) If the substance is classified as a Category II potential carcinogen, the final standard shall conform to the provisions of section 1990.142(a) (3)(iii). If the final standard contains other provisions that substantially differ from the proposed provisions, the Secretary shall explain the reasons for the changes in the preamble to the final standard.

(f) If the suhstance is classified as a Category II potential carcinogen, the Secretary shall notify. the applicable federal and statc agencies, including the Administrator of EPA, the Dlrector of NCI, the Director of NIEHS, the Director of NIOSH, the Commissioner of FDA and the Chairperson of CPSC of such determination and request that the applicable agencies engage in, or stimulate, further research pursuant to their legislative authority, to develop new and additional scientific data.

(g) If, after a rulemaking, the Secretary determines that the substance under consideration should not be classified as a Category II potential carcinogen, the Secretary shall publish a notice of this determination in the Federal Register, together with the reasons therefor.

\section{MODEL STANDARDS}

\subsection{1-MODEL STANDARD PURSUANT TO SECTION 6(b) OF THE ACT}

\section{(a) Scope and application.}

(1)Generol. This section applies to all occupational exposures to __ or to ispecify those uses or classes of uses of [Chemical Abstracts Service Registry Number 0000] which are covered by the standard, including, where appropriate, the type of exposure to be regulated by the standard) except as provided in paragraph (a)(2).
(2) Exemptions. This section does not apply to (insert thuse uscs or classes of uses of which are exempted from compliance with the standard, including, where appropriate,

(i) workplaces where exposure to results from solid or liquid mixtures containing a specified percentage of or less;

(ii) workplaces where another Federal agen- 
cy is exercising statutory authority to prescribe or enforce standards or regulations affecting occupational exposure to or

(iii) workplaces which are appropriately addressed in a separate standard).

\section{(b) Definitions.}

"means (definition of the substance, group of substances, or combination of substances, to be regulated).

"Authorized person" means any person specifically authorized by the employer whose duties require the person to enter regulated areas or any person entering such an area as a designated representative of employees for the purpose of exercising the opportunity to observe monitoring procedures under paragraph ( $r$ ) of this section.

"Action level" means an airborne concentration of _ـ of (insert appropriate level of exposure).

Note. - Where appropriate, consider an action level as a limitation on requirements for periodic monitoring (para. (e)(3)). medical surveillance (para. (n)), training (para. (o)). labels (para. (p)(3)), and other provisions.

"Assistant Secretary" means the Assistant Secretary of Labor for Occupational Safety and Health, U.S. Department of Labor, or designee.

"Director" means the Director, National Institute for Occupational Safety and Health, U.S. Department of Health, and Health Services, or designee.

"Emergency" means in any occurrence such as, but not limited tn, equipment failure, rupture of containers, or failure of control equipment which may result in a massive release of

"OSHA Area Office" means the Area Office of the Occupational Safety and Health Administration having jurisdiction over the geographic area where the affected workplace is located.

\section{(c) Permissible exposure limits provi.} sions.

\section{(1) Inhalation.}

(i) Time-weighted average limit (TWA).
Within (insert appropriate time period) of the effective date of this section, the employ. er shall assure that no employee is exposed to an airborne concentration of excess of: (insert appropriate exposure limit representing: (a) the lowest feasible level, except as modified by paragraph (c)(3) of this section or (b) when it is determined by the Secretary that there are available substitutes for all uses or classes of users that are less hazardous to humans, the proposal shall permit no occupational exposure) as an eight (8)-hour time-weighted average.

Where the Secretary finds that substitutes for may exist, the determination of the lowest feasible level shall include consideration of the availability, practicability, relative degree of hazard, and economic consequences of the substitutes.

(ii) Ceiling limit. (If appropriate.) Within (insert appropriate time period) of the effective date of this section, the employer shall assure that no employee is exposed to an airborne concentration of in excess of: (insert exposure limit representing the low est feasible level of exposure as averaged over any: (insert appropriate time period) during the working day.

(2) Dermal and eye exposure. (As appropriate.)

(i) Within (insert appropriate time period) of the effective date of this section, the employer shall (If eye exposure to does not create a risk of cancer, insert exposure level or criteria which will prevent other adverse health effects of eye exposure to _ـ if any. If eye exposure creates a risk of cancer, insert exposure level or criteria which represent the lowest feasible level of eye exposure to

(ii) Within (insert appropriate time period) of the effective date of this section, the employer shall (Insert exposure level or criteria which will prevent other adverse health effects from skin epposure to or which represent the lowest feasible level of skin exposure to or, as appropriate.)

(3) (If appropriate, specify limitations or prohibitions on consumpton, storage or use of food, 
beverages, smoking materials, etc. in certain workplaces.)

(4) Other restrictions. The employer shall assure that there is no occupational exposure to from the following uses or classes of uses: (Where the Secretary determines, in the proposal or upon the record of the public rulemaking, that there are available substitutes in certain applications where _._. might otherwise be used, the Secretary here may specify that no occupational exposure to shall be permitted in those circumstances and uses, listing those circumstances or. uses. Where the Secretary finds that substitutes for exist, the determination of their suitability shall Include conoideration of the availability, practicability, relative degree of hazard, and economic consequences of the substitutes.)

\section{(d) Notification of use and emergencies.}

(1) Use. Within (insert appropriate time period), of the effective date of this standard or within thirty days of the introduction of into the workplace, every employer who has a place of employment in which is present shall report the address and location of each place of employment to the OSHA Area Office and an estimate of the number of employees exposed.

(2) Emergencies. Emergencies, and the facts obtainable at that time, shall be reported within (iusert appropriate number) hours of, or during the first federal working day after, the time the employer becomes aware of the emergency to the OSHA Area Office, whichever is longer. Upon request of the OSIIA Arca Office, the employer shall submit additional information in writing relevant to the nature and extent of employee exposures and measures taken to prevent future emergencies of a similar nature.

\section{(e) Exposure monitoring.}

\section{(1) General.}

(i) Determinations of airborne exposure levels shall be made from air samples that are representative of each employee's expo. sure to o over an eight (8) hour period. Monitoring of exposure levels required under this paragraph shall be made as fol- lows: (insert method or alternative methods to be used to meet the requirements of this paragraph).

(ii) For the purpose of this section, employee exposure is that exposure which would occur if the employee were not using a respirator.

(2) Initial monitoring. Each employer who has one or more workplaces where Ispecify the types of workplaces subject to the monitoring requirement) shall, within (insert appropriate period) of the effective date of this section (insert requirements for initial monitoring, as appropriate).

(3)Frequency. (Insert, if appropriate, provisions prescriblng lhe minimum frequency at which monitoring must be repeated, the conditions under which such frequency must be increased or may be reduced, and conditions under which such routine monitoring may be discontinued (for example, where the action level is not exceeded). Where appropriate, specify different frequency requirements for certain types of workplaces where, for example, exposure levels are subject to greater or less variability.)

(4) Additional monitoring. (Insert, if appropriate, provisions for monitoring, in addition to the requirements (if any) of paragraph (e)(3). This may include a production, process, control or personnel change which might result in new or additional exposure to ever the emplnyer has any other reason to suspect a change which might result in new or additional exposurce to

\section{(5) Employee notification.}

(i) Within (insert apprupriate pcriod) after the receipt of monitoring results, the employer shall notify each employee in writing of the results which represent that employee's exposure.

(ii) Whenever the results indicate that the representative employee exposure exceeds the permissible exposure limits, the employer shall include in the written notice a statement that the permissible exposure limits were exceeded and a description of the correctlve action being taken to reduce exposure to or below the permissible exposure limits. 
(6) Accuracy of measurement. (Insert requirements for accuracy of methods of measurement or detection used to comply with the paragraph).

\section{(f) Regulated areas.}

(1) Within (insert appropriate time period) of the effective date of this section, the employer shall, where practicable, establish regulated areas where concentrations are in excess of the permissible exposure limits.

(2) Regulated areas shall be demarcated and segregated from the rest of the workplace, in any manner that minimizes the number of persons who will be exposed to

(3) Access to regulated areas shall be limited to authorized persons or to persons otherwise authorized by the Act or regulations issued pursuant thereto.

(4) The employer shall assure that in the regulated area, food or beverages are not present or consumed, smoking products are not present or used, and cosmetics are not applied (except that these activities may be conducted in the lunchroom, change rooms and showers required under paragraphs $(m)(1)-(m)(3)$ of this section).

\section{(g) Methods of compliance.}

\section{(1) Engineering ond work practice controls.}

(i) The employer shall institute engineering or work practice controls to reduce and maintain employee exposures to ___ to or below the permissible exposure limits, except to the extent that the employer catablishes that such controls are not feasible.

(ii) Engineering or work practice controls shall be implemented to reduce exposures even if they will not be sufficent to reduce exposures to or below the permissible exposure limits.

\section{(2) Compliance program.}

(i) Within (insert appropriate period) of the effective date of this section, the employer shall establish and implement a written program to reduce exposures to or below the permissible exposure limits by means of engineering and work practice controls, as required by paragraph $(\mathrm{g})(1)$ of this section.

(ii) Written plans for these compliance programs shall include at least the following:

(a) A description of each operation or process resulting in employee exposure to

(b) Engineering plans and other studies contemplated or used to determine the controls for each process;

(c) A report of the technology considered or to be considered in meeting the permissible exposure limits;

(d) A detailed schedule for the implementation of engineering or work practice controls; and

(e) Other relevant information reasonably requested by OSHA.

(iii) Written plans for such a program shall be submitted, upon request, to the Assistant Secretary and the Director, and shall be available at the worksite for examination and copying by the Assistant Secretary, the Director, or any affected employee or desig. nated representative.

(iv) The plans required by this paragraph shall be revised and updated periodically to reflect the current status of the program.

\section{(h) Respiratory protection.}

(1) Generol. The employer shall assure that respirators are used where required pursuant to this section to reduce employee exposures to within the permissible exposure limits and in emergencies. Compliance with the permissible exposure limits may not be achieved by the use of respirators except:

(i) During the time period necessary to install or implement feasible engineering and work practice enntrols; or

(ii) In work operations in which the employer establishes that engineering and work practice controls are not feasible; or 
STANDARDS AND INTERPRETATIONS

(iii) In work situations where feasible engineering and work practice controls are not yet sufficient to reduce exposure to or below the permissible exposure limits; or

(iv) In emergencies.

\section{(2) Respirator selection.}

(i) Where respiratory protection is required under this section, the employer shall select and provide at no cost to the employee, the appropriate type of respirator from Table 1 helow and shall assure that the employee wears the respirator provided.

Table 1.-Respiratory Protection for

(The table will contain a listing of the appropriate type of respirator for various conditions of exposure to ) ).

(ii) The employer shall select respirators from those approved by the National Institute for Occupational Safety and Health under the provisions of 30 CFR Part 11.

\section{(3) Respirator program.}

(i) The employer shall institute a respiratory protection program in accordance with 29 CFR 1910.134 (b), (d), (e), and (f).

(ii) Employees who wear respirators shall be allowed to wash their face and respiiator facepeice to prevent potential skin irriation associated with respirator use.

(iii) The employer shall assure that the respirator issued to each empluyee is propor. ly fitted (as appropriate, indicate the requirement for a qualitative or quántltative Iespi. rator fit testing program).

\section{(i) Emergency situations.}

(1) Written plans.

(i) A written plan for emergency situations shall be developed for each workplace where is present. Appropriate portions of the plan shall be implemented in the event of an emergency. (ii) The plan shall specifically provide that employees engaged in correcting emergency conditions shall be equipped as required in paragraph $(h)$ of this section until the emer. gency is abated.

\section{(2) Alerting employees.}

(i) Alarms. Where there is the possibility of employee exposure to _ue to the occurance of an emergency, a general alarm shall be installed and maintained to promptly alert employees of such occurrences.

(ii) Evacuation. Employees not engaged in correcting the emergcncy shall he restricted from the area and shall not be permitted to return until the emergency is abated.

\section{(i) Protective clothing and equipment.}

(1) Provision and use. Where employees are exposed to eye or skin contact with (insert criteria which trigger this requirement as appropriate), the employer shall, within (insert appropriate time period) of the effective date of this section provide at no cost to such employees, and assure that such employees wear, appropriate protective clothing or other equipment in accordance with 29 CFR 1910.132 and .133 to protect the area of the body which may come in contact with

\section{(2) Cleaning and replacement.}

(i) 'The employer shall clcan, launder, mainlaiu, or roplace protective clothing and equipment required to maintain their effectiveness.

\section{(k) Housekeeping}

(1) General. The employer shall, within appropriate time perlod of the effective date of this section, implement a housekeeping program to maximize accumulation of

(i) The program shall include (Insert appro. priate elements).

(a) Periodic scheduling of routine housekeeping.

(b) Provision for periodic cleaning of dust collection systems. 
(c) Provision for maintaining clean surfaces.

(d) Provision for assigning personnel to housekeeping procedures.

(e) Provision for informing employees about housekeeping program.

\section{(I) Waste disposal.}

(1) Generol. The employer shall assure that no waste material containing ___ is dispersed into the workplace, to the extent practicable.

(2) The employer shall lable, or otherwise inform employees who may contact waste material containing such waste material.

(3) (Insert specific disposal methods, as appropriate.)

\section{(m) Hygiene facilities and practices.}

Where employees are exposed to airborne concentrations of in excess of the permissible exposure limits specified in paragraph (c)(1), or where employees are required to wear protective clothing or equipment pursuant to paragraph (j) of this section, or where otherwise found to be appropriate, the facilities required by 29 CFR 1910.141 shall be provided by the employer for the use of those employees and the employer shall assure that the employees use the facilities provided. In addition, the following additional facili. ties or requirements may be mandated.

[Specify as appropriate additional facilities and practices such as]:

(1) Change rooms. The employer shall provide clean change rooms in accordance with 29CFR $1910.141(\mathrm{e})$.

\section{(2) Showers.}

(i) The employer shall provide shower facilities in accordance with 29 CFR 1910.141(d)(3).

(ii) In addition, the employer shall also assure that employees exposed to shower at the end of the work shift.

(3) Lunchrooms. (as appropriate) Whenever food or beverages are consumed in the workplace, the employer shall provide lunchroom facilities which have a temperature controlled, positive pressure, filtered air supply, and which are readily accessible to employees exposed to

\section{(n) Medical surveillance.}

\section{(1) General.}

(i) Within (insert appropriate period) of the effective date of this section, the employer shall institute a program of medical surveillance for (specify the types of employees subject to the medical surveillance requirement, for example, by specifying the level, duration, and frequency of exposure to which make medical surveillance feasible and appropriate for individual employees). The employer shall provide each such employee with an opportunity for medical examinations and tests in accordance with this paragraph.

(ii) The employer shall assure that all medical examinations and procedures are performed by or under the supervision of a licensed physician, and shall be provided without cost to the employee.

(2) Initiol examinations. At the time of initial assignment, or upon institution of the medical surveillance program, the employer shall provide each employee specified in paragraph $(n)(1)$ of this section an opportunity for a medi. cal examination, including at least the following elements:

(i) A work history, a medical history, and a physical examination with direct emphasis towards (insert specific bodily organs or sys. tems), and shall include the personal history of the employee, family, and occupational background. (Specify additional factors to be considered, including, as pertinent to the specific health hazard(s) posed by genetic and environmental factors.)

(ii) The medical examination shall also include the following: (insert appropriate medical protocol. Where appropriate, provide that the examining physician shall conduct such examinations and tests as are needed according to his professional judgement). 
STANDARDS AND INTERPRETATIONS

Note. - Where appropriate, require or permit different medical protocols, or different frequencies of medical examinations, for separate sub-populations of employees covered under paragraph (n)(1).

(3) Periodic examinations.

(i) The employer shall provide the examinations specified below at least (insert appropriate time) for all employees specified in paragraph $(n)(1)$ of this section: (insert appropriate medical protocol for periodic examinations).

(II) If an cmployee has not had the examinations prescribed in paragraph $(n)(2)$ of this section within linsert apprupriate time poriod) prior to termination of employment, the employer shall make such examination available to the employee upon such termination.

(4) Additional examinations. If the employee for any reason develops signs or symptoms commonly associated with exposure to the employer shall provide appropriate examination and emergency medical treatment.

(5) Information provided to the physician. The employer shall provide the following information to the examining physician:

(i) A copy of this standard and its appendices;

(ii) A description of the affected employee's duties as they relate to the employee's exposure;

(iii) The employee's representative exposure level;

(iv) The employee's anticipated or estimated exposure level (for preplacement examinations or in cases of exposure due to an emergency);

(v) A description of any personal protective equipment used or to be used; and

(vi) The names and addresses of physicians who, under the sponsorship of the employer, provided previous medical examinations of the affected employee, if such records are not otherwise available to the examining physician.
(6) Physicion's written opinion.

(i) The employer shall obtain a written opinion from the examining physician which shall include:

(a) The physician's certification that he has received the information from the employer required under the paragraph (n)(5) and has performed all medical examinations and tests which are in his opinion appropriate under this standard;

(b) The physician's opinion as to whether the employee has any detected medical condition which would place the empluyee at an incedsed risk of material impairment of the employee's health for txposurc to

(c) Any recommended limitations upon the employee's exposure to ___ or upon the use of protective clothing and equipment such as respirators; and

(d) A statement that the employee has been infomed by the physician of the results of the medical examination and any medical conditions which require further examination or treatment.

(ii) The employer shall instruct the physician not to reveal in the written opinion specific findings ur diagnoses unrelated to ns.cupational exposure to

(iii) The employer shall provide a copy of the written opininn to the affected employee.

\section{(o) Employee Information and Training.}

\section{(1) Training Program.}

(i) Within (insert appropriate period) of the effective date of this section, the employer shall institute a training program for all employees who (specify the rmployees suhject to the training requirement), and shall require their participation in the training program.

(ii) The training program shall be provided at the time of initial assignment, or upon institution of the training program, and at least (insert appropriate time period) there 
after, and the employer shall assure that each employee is informed of the following:

Note.-Specify, as appropriate, some or all of the following information, or any other appropriate information.

(a) The information contained in the Appendices;

(b) The quantity, location, manner of use, release or storage of ___ and the specific nature of operations which could result in exposure to $\longrightarrow$, as well as any necessary protective steps;

(c) The purpose, proper use, and limitations of respirators;

(d) The purpose and a description of the medical surveillance program required by paragraph $(n)$ of this section;

(e) The emergency procedures developed, as required by paragraph (i) of this section;

(f) The engineering and work practice controls, their function and the employee's relationship thereto; and

Note. - Where appropriate, require training programs with different contents, or different frequencies, for separate subpopulations of the employees specified in paragraph $(0)(1)$.

(g) A review of this standard.

(2) Access to training materials.

(i) The employer shall make a copy of this standard and its appendices readily a vailable to all affected employees.

(ii) The employer shall provide, upon request, all materials relating to the employee information and training program to the Assistant Secretary and the Director.

\section{(p) Signs and labels.}

\section{(1) General.}

(i) The employer may use labels or signs required by other statutes, regulations, or ordinances in addition to, or in combination with, signs and labels required by this paragraph. (ii) The employer shall assure that no statement appears on or near any sign or label, required by this paragraph, which contradicts or detracts from the meaning of the required sign or label.

\section{(2) Signs.}

(i) The employer shall post signs to clearly indicate all workplaces where __ may be present or where exposures exceed the action level. The signs shall bear the following legend:

\section{DANGER}

(insert appropriate trade or common names)

\section{CANCER HAZARD}

\section{AUTHORIZED PERSONNEL ONLY}

(ii) The employer shall assure that signs required by this paragraph are illuminated and cleaned as necessary so that the legend is readily visible.

(iii) Where airborne concentrations of exceed the permissible exposure limits, the signs shall bear the additional legend: "Respirator Required"

\section{(3) Labels.}

(i) The employer shall assure that precautionary lables are affixed to all containers of and of products containing , and that the labels remain affixed when the or products containing are sold, distributed or otherwise leave the employer's workplace.

(ii) The employer shall assure that the precautionary lables required by this paragraph are readily visible ând legible. The labels shall bear the following legend:

\section{DANGER \\ CONTAINS \\ CANCER HAZARD}

\section{(q) Recordkeeping}

\section{(1) Exposure monitoring.}

(i) The employer shall establish and main- 


\section{STANDARDS AND INTERPRETATIONS}

tain an accurate record of all monitoring required by paragraph (e) of this section.

(ii) This record shall include:

(a) The dates, number, duration, and results of each of the samples taken, including a description of the samples taken, including a description of the sam. pling procedure used to determine representative employees exposure;

(b) A description of the sampling and analytical methods used;

(c) Type of rcopiratory protective devices worn, if any; and

(d) Name, social security number and job. classification of the employee monitored and of all other employees monitored and of all other employees whose exposure the measurement is intended to represent.

(iii) The employer shall maintain this record for (insert appropriate period) or for the duration of employment plus (insert appropriate period) whichever is longer.

(2) Medical surveillance.

(i) The employer shall establish and main. tain an accurate record of each employee sub. ject to medical surveillance as required by paragraph $(n)$ of this section.

(ii) This record shall include:

(a) A copy of the physicians' written opin. ions;

(b) Any employees medical complaints related to exposure lu

(c) A copy of the information provided to the physician as required by paragraph $(n)(6)$ of this section; and

(d) A copy of the employee's work history.

(iii) The emplnyer shall assure that this record be maintained for (insert appropriate period) or for the duration of employment plus (insert appropriate period) whichever is longer.
(3) Availability.

(i) The employer shall assure that all records required to be maintained by this section be made available upon request to the Assistant Secretary and the Director for examination and copying.

(ii) The employer shall assure that employee exposure measurement records, as required by this section, be made avallable, upon request, for examination and copying to the affected employee, former employee, or designated representative.

(iii) The employer shall assure that empluyee modical records required to be maintained by this section, be made available, upon request, for examination and copying, to the affected employee or former employee, or to a physician designated by the affected employee, former employee, or. designated by the affected employee, former employee, or designated representative.

\section{(4) Transfer of records.}

(i) Whenever the employer ceases to do business, the successor employer shall receive and retain all records required to be maintained by this section.

(ii) Whenever the employer ceases to do business and there is no successor employer to receive and retain the records for the prescribed period, these records shall be transmitted to the Direclor.

(iii) At the expiration of the retention period for the records required to be maintained pursuant to this section, the employer shall transmit these records to the Director.

\section{(r) Observation of monitoring.}

(1) Employee observation. The employer shall providu affectcd emplnyeps, or their designated representatives, an opportunity to observe any monitoring of employee exposure to conducted pursuant to paragraph (e) of this section.

\section{(2) Observation procedures.}

(i) Whenever observation of the monitorin" 
of employee exposure to requires entry into an area where the use of protec. tive clothing or equipment is required, the employer shall provide the observer with personal protective clothing or equipment required, the employer shall provide the observer with personal protective clothing or equipment required to be worn by employees working in the area, assure the use of such clothing and equipment, and require the observer to comply with all other applicable safety and health procedures.

(ii) Without interfering with the montoring, observers shall be entitled to:

(a) Receive an explanation of the measurement procedures;

(b) Observe all steps related to the meas- urement of airborne concentrations of sure; and performed at the place of expo-

(c) Record the results obtained.

(s) Effective date. This section shall become effective (insert effective date).

(t) Appendices. The information contained in the appendices is not intended, by itself, to create any additional obligations not otherwise imposed or to detract from any existing obligation.

$\underset{*}{\text { Appendix A-Substance Safety Data Sheet }}$ *

Appendix B-Substance Technical Guidelines

Appendix $C-$ Medical Surveillance Guidelines

\subsection{MODEL EMERGENCY TEMPORARY STANDARD PURSUANT TO SECTION 6(c)}

Occupational Exposure to Emergency Temporary Standard

\subsection{0}

\section{(a) Scope and Application.}

(1) General. This section applies to all occupational exposures to , or to (specify the uses or classes of uses of _...._._. [Chemical Abstracts Service Registry Number 00000], which are covered by the standard, including, where appropriate, the type of exposure to be regulated by the standard) except as provided in paragraph (a)(2).

(2) Exemption. This section does not apply to (insert thuse uses or classes of uses of which are exempted from compliance with the standard, including, where appropriate,

(i) workplaces where exposure to results from solid or liquid mixtures containing a specified percentage of or less; (ii) workplaces where another Federal agency is exercising statutory authority to prescribe or enforce standards or regulations affecting occupational exposure to or

(iii) workplaces which are appropriately addressed in a separate standard.

\section{(b) Definitions.}

"__ means (definition of the substance, group of substances, or combination of substances, to be regulated).

"Authorized person" means any person specifically authorized by the employer whose duties require the person to enter a regulated area or any person enteriug such àn area as a designated representative of employees exercising the opportunity to observe monituring procedures under paragraph ( $r$ ) of this section.

"Action level" means an airborne concentration of $\ldots$ of (insert appropriate level of exposure). 
STANDARDS AND INTERPRETATIONS

(Note: where appropriate, consider an action level as a limitation on requirements for periodic monitoring (para.(e)(3)), medical surveillance (para. (n)), training (para. (o)), and other provisions.]

"Assistant Secretary" means the Assistant Secretary of Labor for Occupational Safety and Health, U.S. Department of Labor, or designee.

"Director" means the Director, National Institute for Occupational Safety and Health, U.S. Department of Health, Education and Welfare, or designee.

"Emergcncy" means any occurrence such as, but not limited to, equipment failure, rupture of containers, or failure of curitrol equipment which may result in a massive relase of

"OSHA Area Office" means the Area Office of the Occupational Safety and Health Administration having jurisdiction over the geographic area where the affected workplace is located.

\section{(c) Permissible exposure limits}

(1) Inhalation.

(i) Time-weighted average limit (TWA). Within (insert appropriate time) from the effective date of this emergency temporary standard, the employer shall assure that no employee is exposed to an airborne concentration of - in excess of: (insert appropriate exposure linit representing the lowest feasible level that can be complled with immediately) as an eight ( 8 )-hour timc weighled avorago.

(ii) Ceiling limit. (If appropriate.) The employer shall assure that no employee is exposed to an airborne concentration as of in excess of: (insert appropriate exposure limit representing the lowest feasi. ble level that can be complied with immediately) as averaged over any: (insert appropriate time perion) during the working day.

(2) Dermal and eye exposure (As appropriate.) The employer shall assure that no employee is exposed to eye contact or skin contact with

(i) Within (insert appropriate time period) of the effective date of this section, the employer (If eye exposure to __ does not create a risk of cancer, insert exposure level or criteria which will prevent other adverse effects of eye exposure to

if any. If eye exposure creates a risk of cancer, insert exposure level or criteria which represent the lowest feasible level of eye exposure to

(ii) Within (insert appropriate time period) of the effective date of this section, the employer shall (Insert exposure level or criteria which will prevent other adverse health effects from skin exposure to ___ or which represent the lowest feasible level of skin exposure to , as appropriate.)

(3) (If appropriate, specify limitations or prohibitions on consumption, storage or usc of food, beverages, smoking materials, etc. in certain workplaces.)

(d) Notification of Use. Within (insert appropriate time) of the effective date of this section, or within fifteen (15) days following the introduction of $\quad$ into the workplace, every employer shall report the following information to the nearest OSHA Area Office for each such workplace:

(1) The address and location of each workplace in which is present;

(2) A brief description of each process or operation which may result in employee exposure to

(3) The number of employees engaged in ouch prucess or operation who may be exposed and an estimate of the frequency and degree of exposure that occurs; and

(4) A brief description of the employer's safety and health program as it relates to limitation of employee exposure to

\section{(e) Exposure monitoring.}

\section{(1) General.}

(i) Determinations of airborne exposure levels shall be made from air samples that are representative of each employee's exposure to __ over an eight (8) hour peri. od. Monitoring of exposure levels required under this paragraph shall be made in 
follows: [insert method or alternative methods to be used to meet the requirements of this paragraph].

(ii) For the purposes of this section, employee exposure is that exposure which would occur if the employee were not using a respirator.

(2) Initial monitoring. Each employer who has one or more workplaces where (specify the types of workplaces subject to the monitoring requirement), shall within (insert appropriate period) of the effective date of this section (insert requirements for initial monitoring, as appropriate).

(3) Frequency. (Insert, if appropriate, provisions prescribing the minimum frequency at which monitoring must be repeated, the conditions under which such frequency must be increased, or may be reduced, and conditions under which such routine monitoring may be discontinued (for example where the action level is not exceeded) where appropriate, specify different frequency requirements for certain types of workplaces where, for example, exposure levels are subject to greater or less variability.)

(4) Additional monitoring. (Insert, if appropriate, provisions for monitoring, in addition to the requirements (if any) of paragraph (e)(3). This may include a production, process, control or personnel change which might result in new or additional exposure to or whenever the employer has any other reason to suspect a change which might result in new or additional exposures to .)

\section{(5) Employee notification.}

(i) Within (insert appropriate period) after the receipt of monitoring results, the employer shall notify each employee in writing of the results which represent that employee's exposure.

(ii) Whenever the results indicate that the representative employee exposure exceeds the permissible exposure limits, the employer shall include in the written notice a statement that permissible exposure limits were exceeded and a description of the corrective action being taken to reduce expo- sure to or below the permissible exposure limits.

(6) Accuracy of measurement. (Insert requirements for accuracy of methods of measurement or detection used to comply with the paragraph.)

\section{(f) (Reserved.)}

\section{(g) Methods of compliance.}

(1) General. Employee exposures to shall be controlled to or below the permissible exposure limits by any practicable combination of engineering controls, work practices and personal protective devices and equipment, during the effective period of this emergency temporary standard.

\begin{abstract}
Note. - Where engineering controls or work practices can reduce employee exposures to __ it is recommended that they be implemented where practicable, even where they do not themselves reduce exposures to, or below the permissible exposure limits. Work practices which can be implemented by the employer to help reduce employee exposures to ___ include limiting access to work areas to authorized personnel, prohibiting smoking and consumption of food and beverages in work areas, and establishing good maintenance and housekeeping practices, including the prompt clean-up of spills and repair of leaks.
\end{abstract}

(2) Engineering and work practice control plan.

(i) Within (insert appropriate time period) of the effective date of this emergency temporary standard, the employer shall develop a written plan describing proposed means to reduce employee exposures to the lowest feasible level solely by means of engineering and work practice controls (which will be eventually required by a permanent standard for occupational exposure to issued pursuant to section $1990.160(\mathrm{~g})$ of this subpart).

(ii) Written plans required by this paragraph shall be submitted, upon request, to the Assistant Secretary and Director and shall be available at the worksite for examination and copying by the Assistant Secretary, the Director, and any affected employee or designated representative.

\section{(h) Respiratory protection}

(1) Required use. The employer shall assure 
STANDARDS AND INTERPRETATIONS

that respirators are used where required pursuant to this section to reduce employee exposures to within the permissible exposure limits and in emergencies.

(2) Respirator selection.

(i) Where respiratory protection is required under this section, the employer shall select and provide at no cost to the employee, the appropriate respirator from Table 1 below and shall assure that the employee wears the respirator provided.

Table 1. - Respiratory Protection for

The table will contain a listing of the appropriate type of respirator for various conditions of exposure to .)

(ii) The employer shall select respirators from those approved by the National Insti. tute for Occupational Safety and Health under the provisions of 30 CFR Part 11.

\section{(3) Respirator program.}

(i) The employer shall institute a respirator protection program in accordance with 29 CFR 1910.134 (b), (d), (e) and (f).

(ii) Employees who wear respirators shall be allowed to wash their face and respirator face piece to prevent potential skin irritation associated with respirator use.

(iii) The employer shall assure that the respirator issued to each employee is properly fitted (as appropriate, indicate the requirement for a qualitative or quantitative respirator fit testing program !

\section{(i) (Reserved.)}

\section{(i) Protective clothing and equipment.}

(1) Provision and use. Where employees are exposed to eye or skin contact with

(insert criteria which trigger this requirement as appropriate), the employer shall within (insert appropriate time period) of the effective date of this standard provide, at no cost to the employees, and assure that employees wear, appropriate protective clothing or other equipment in accordance with 29 CFR 1910.132 and .133 to protect the area of the body which may come in contact with

\section{(2) Cleaning and replacement.}

(i) The employer shall clean, launder, maintain, or replace protective clothing and equipment required by this paragraph, as needed to maintain their effectiveness.

\section{(k) Housekeeping.}

(1) Conoral. The empluyer shall; within (inoert appropriate time period) of the effectlve date of this section, implement a housekeeping pro. gram to minlmize accuinulations of

(i) The program shall include (insert appropriate elements):

(a) Perindic scheduling of routine housekeeping procedures;

(b) Provision for periodic cleaning of dust collection systems;

(c) Provisioñ for maintaining clean sur. faces;

(d) Provision for assigning personnel to housekeeping procedures; and

(e) Provision for informing employees about housekeeping program.

\section{(I) Waste disposal.}

(1) General. The employer shall assure that no waste material containing __ is dispersed into the workplace, to the extent practicable.

(2) The employer shall label, or otherwise inform employees who may contact waste material containing such waste material. of the contents of

(3) (Insert specific disposal methods, as appropriate.)

(m) (Reserved). 


\section{n) Medical surveillance.}

\section{(1) General.}

(i) The employer shall institute a program of medical surveillance for each employee who is or will be exposed to $\ldots$ The employer shall provide each such employee with an opportunity for medical examinations and tests in accordance with this paragraph.

(ii) The employer shall assure that all medical examinations and procedures are performed by or under the supervision of a licensed physician, and shall be provided without cost to the employee.

(2) Initial examinations. Within (insert appropriate time period) of the effective date of this section, or thereafter at the time of initial assignment, the employer shall provide each affected employee an opportunity for a medical examination, including at least the following elements:

(i) A work history, a medical history, and a physical examination with direct emphasis towards (insert appropriate systems) which shall include the relevant personal history of the employee, family, and occupational background. (Specify additional factors to be considered, including, as pertinent to the specific health hazard(s) posed by genetic and environmental factors.)

(ii) The medical examination shall also include the following: (insert appropriate medical protocol. Where appropriate, provide that the examining physician shall conduct such examinations and tests as are needed according to his professional judgement)

[Note: Where appropriate, require or permit different medical protocols, or different frequencies of medical examinations, for separate sub-populations of employees covered under paragraph $(n)(1))$.

(3) Periodic exominations. (Insert appropriate medical protocol and time.)

(4) Interim examinations. If the employee for any reason develops signs or symptoms commonly associated with exposure to the employer shall provide appropriate examination and emergency medical treatment.

(5) Information provided to the physician. The employer shall provide the following information to the examining physician:

(i) A copy of this emergency temporary standard and its appendices;

(ii) A description of the affected employee's duties as they relate to the employee's exposure;

(iii) The employee's representative exposure level;

(iv) A description of any personal protective equipment used or to be used; and

(v) The names and addresses of physicians who, under the sponsorship of the employer, provided previous medical examinations of the affected employee, if such records are not otherwise available to the examining physician.

(6) Physicion's written opinion.

(i) The employer shall obtain a written opin. ion from the examining physician which shall include:

(a) The results of the medical tests performed;

(b) The physician's opinion as to whether the employee has any detected medical conditiun which would place the employee at an increased risk of material impairment of the employee's health from exposure to

(c) Any recommended limitations upon the employee's exposure to _ or upon the use of protective clothing and equipment such as respirators; and

(d) A statement that the employee has been informed by the physician of the results of the medical examination and any medical conditions which require further examination or treatment.

(ii) The employer shall instruct the physi- 
STANDARDS AND INTERPRETATIONS

cian not to reveal in the written opinion specific findings or diagnoses unrelated to occupational exposure to

(iii) The employer shall provide a copy of the written opinion to the affected employee.

\section{(o) Employee information and training.}

\section{(1) Troining progrom}

(i) Within (insert appropriate time period) from the effective date of this standard, the employer shall institute a training program for all employees where there is occupational expousure to and shall assurc thcir participation in the training program.

(ii) The employer shall assure that each employee is informed of the following:

(a) The information contained in the Appendices;

(b) The quantity, location, manner of use, release, or storage of and the spe-

cific nature of operations which could result in exposure to _ as well as any necessary protective steps;

(c) The purpose, proper use, and limitations of respirators;

(d) The purpose and description of the medical surveillance program required by paragraph (n) of this section; and

(e) A review of this standard.

\section{(2) Access to training moterials.}

(i) The employer shall make a copy of this standard and its appendices readily available to all affected emplnyees.

(ii) The employer shall provide, upon request, all materials relating to the employee information and training program to the Assistant Secretary and the Director.

\section{(p) (Reserved.)}

\section{(q) Recordkeeping.}

\section{(1) Exposure monitoring.}

(i) The employer shall establish and maintain an accurate record of all monitoring required by paragraph (e) of this section.

(ii) This record shall include:

(a) The dates, number, duration, and results of each of the samples taken, including a description of the sampling procedures used to determine representative employee exposure;

(b) A description of the sampling and analytical methods used;

(c) Type of respiratory protective devices worn, if any; and

(d) Name, social security number, and job classification of the employee monitored and of all other employees whose exposure the measurement is intended to represent.

(iii) The employer shall maintain this record for the effective period of this emergency temporary standard and for any additional period required by the permanent standard.

(2) Medical surveillance.

(i) The employer shall establish and maintain an accurate record for each employee subject to medical surveillance as required by paragraph $(\Omega)$ of this section.

(ii) This record shall include:

(a) A copy of the physicians' written opinions.

(b) Any employee medical complaints related to exposure to

(c) A copy of the information provided to the physician as required by paragraph $(n)(6)$ of this section; and

(d) A copy of the employee's work history.

(iii) The employer shall assure that this record be maintained for the effective period of this emergency temporary standard, an ${ }^{\text {J }}$ 
for any additional period required by the permanent standard.

\section{(3) Availability.}

(i) The employer shall assure that all records required to be maintained by this section be made available upon request, for examination and copying to the affected employee, former employee, or designated representative.

(ii). The employer shall assure that employee exposure measurement records, as required by this section, be made available upon request to the Assistant Secretary and the Director for examination and copying.

(iii) The employer shall assure that employee medical records required to be maintained by this section, be made avail. able, upon request, for examination and copying to the affected employee or former employee, or to a physician designated by the affected employee, former employee, or designated representative.

\section{(r) Observation of monitoring.}

(1) Employee observation. The employer shall provide affected employees, or their designated representatives, an opportunity to observe any monitoring of employee exposure to

(e) of this section.

(2) Observation procedures.

(i) Whenever observation of the monitoring of employee exposure to requires entry into an area where the use of protective clothing or equipment is required, the employer shall provide the observer with personal protective clothing or equipment required to be worn by employees working in the area, assure the use of such clothing and equipment, and require the observer to comply with all other applicable safety and health procedures.

(ii) Without interfering with the monitoring, observers shall be entitled to:

(a) Receive an explanation of measurement procedures;

(b) Observe all steps related to the measurement of airborne concentrations of sure; and performed at the place of expo-

(c) Record the results obtained.

(s) Effective date. This section shall become effective (insert effective date).

(4) Appendices. The information contained in the appendices is not intended, itself, to create any additional obligations not otherwise imposed or to detract from any exisiting obligation.

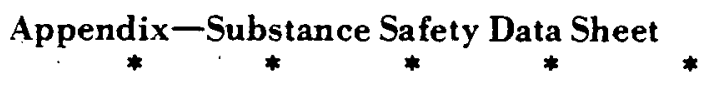

Appendix-Substance Technical Guidelines

Appendix-Medical Surveillance Guidelines 